Document downloaded from:

http://hdl.handle.net/10251/145870

This paper must be cited as:

Tello Oquendo, FM.; Navarro-Peris, E.; Gonzálvez-Maciá, J. (09-2). A comprehensive study of two-stage vapor compression cycles with vapor-injection for heating applications, taking into account heat sink of finite capacity. International Journal of Refrigeration. 93:52-64. https://doi.org/10.1016/j.ijrefrig.2018.05.039

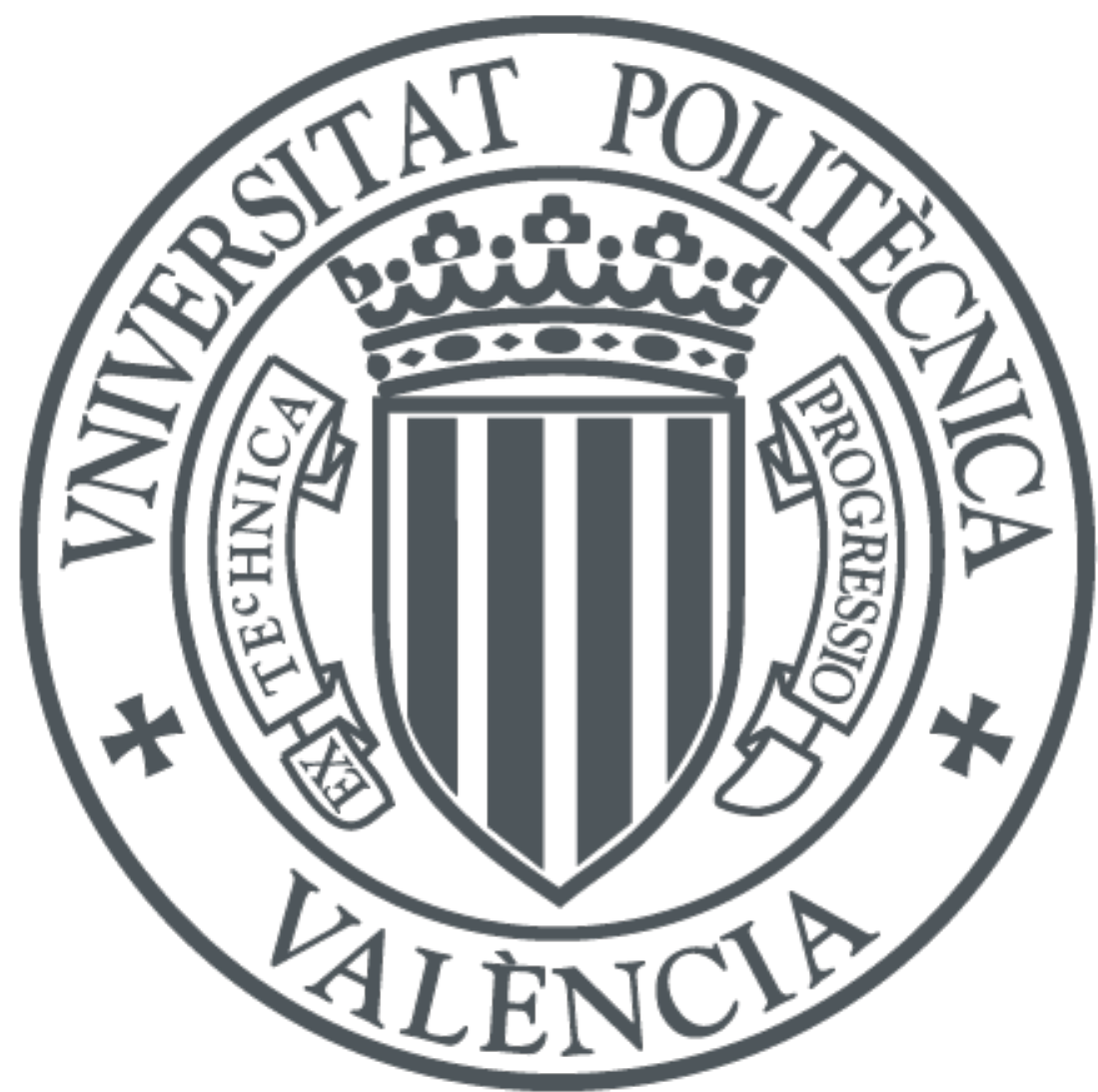

The final publication is available at

https://doi.org/10.1016/j.jirefrig.2018.05.039

Copyright Elsevier

Additional Information 


\title{
A COMPREHENSIVE STUDY OF TWO-STAGE VAPOR COMPRESSION CYCLES WITH VAPOR-INJECTION FOR HEATING APPLICATIONS, TAKING INTO ACCOUNT HEAT SINK OF FINITE CAPACITY
}

\author{
Fernando M. Tello-Oquendo a,*, Emilio Navarro-Peris ${ }^{a}$, José Gonzálvez-Maciá a \\ ${ }^{a}$ Universitat Politècnica de València, Instituto Universitario de Investigación en Ingeniería \\ Energética, Camino de Vera, s/n, Valencia, 46022, Spain. \\ * Corresponding author. Tel.: +34 963879 120, Fax: +34 963879 126, E-mail address: \\ fertelo1@upvnet.upv.es (Fernando Tello)
}

\begin{abstract}
This paper presents a comprehensive study of two-stage vapor compression cycles with vaporinjection for several refrigerants considering that the heat sink has a limited capacity. The key parameters of the cycle performance are identified and the influence of these parameters on the heating COP is analyzed. The optimum intermediate conditions of the cycle are evaluated using a general model of the cycle, considering two configurations (flash tank and economizer). Based on the optimization results, a correlation is proposed in order to estimate the optimum intermediate pressure, taking into account the temperature lift in the secondary fluid imposed by the application. The correlation uses cycle subcooling as an input, which is a novelty from the current correlations proposed in the literature. In addition, an optimum subcooling control strategy is proposed and finally, the influence of the size of the system components on the COP is studied.
\end{abstract}

Keywords: two-stage compression; vapor-injection; flash tank; economizer; optimization; intermediate pressure 


\section{Nomenclature}

A area $\left(\mathrm{m}^{2}\right)$

$\mathrm{C}_{\mathrm{o}} \quad$ coefficient of geometric mean pressures (-)

COP coefficient of performance (-)

DCOP relative difference between COP of twostage and one-stage cycles (\%)

DQ relative difference between capacity of twostage and one-stage cycles (\%)

$D_{R} \quad$ displacement ratio (-)

DT temperature difference (K)

$\dot{\mathrm{E}} \quad$ compressor power input (W)

EV expansion valve

$\mathrm{h} \quad$ enthalpy $\left(\mathrm{J} \mathrm{kg}^{-1}\right)$

LR liquid receiver

$\dot{\mathrm{m}} \quad$ mass flow rate $\left(\mathrm{kg} \mathrm{s}^{-1}\right)$

$\mathrm{N}$ number (-)

$\mathrm{P} \quad$ pressure $(\mathrm{Pa})$

$\dot{\mathrm{Q}} \quad$ capacity $(\mathrm{W})$

$\mathrm{R}^{2} \quad$ correlation factor (-)

SC subcooling (K)

SCVI scroll compressor with vapor-injection

$\mathrm{SH} \quad$ superheat $(\mathrm{K})$

SPF seasonal performance factor (-)

$\mathrm{T}$ temperature $\left({ }^{\circ} \mathrm{C}\right)$

TSRC two-stage reciprocating compressor

$\mathrm{U} \quad$ overall heat transfer coefficient $\left(\mathrm{W} \mathrm{K}^{-1} \mathrm{~m}^{-2}\right)$

$\dot{\mathrm{V}} \quad$ swept volume $\left(\mathrm{m}^{3} \mathrm{~h}^{-1}\right)$

$\mathrm{X}_{\text {inj }} \quad$ injection ratio (-)

\section{Greek symbols}

$\begin{array}{ll}\Delta & \text { difference } \\ \varepsilon & \text { heat exchanger effectiveness (-) } \\ \theta & \begin{array}{l}\text { intermediate relative temperature difference } \\ (-)\end{array} \\ \rho & \text { density }\left(\mathrm{kg} \mathrm{m}^{-3}\right) \\ \eta_{\mathrm{c}} & \text { compressor efficiency (-) } \\ \eta_{\mathrm{v}} & \text { volumetric efficiency (-) }\end{array}$

\section{Subscripts}

b bubble point

C cold

c condenser, cooling

d dew point

dis discharge

e evaporator

eco economizer

$\mathrm{H}$ hot

$\mathrm{h} \quad$ heating

in inlet

inj injection

int intermediate

loss energy loss

max maximum

min minimum

opt optimum

out outlet

$\mathrm{p} \quad$ plate

r ratio, reduced

$\mathrm{S} \quad$ isentropic

sat saturation

w water

1 compressor inlet

2 compressor outlet (first stage)

3 compressor inlet (second stage)

$4 \quad$ compressor outlet (second stage)

5 condenser outlet

6 expansion valve inlet (EV-2)

7 expansion valve outlet (EV-1)

$8 \quad$ injection port inlet

9 evaporator inlet 


\section{INTRODUCTION}

In European Union (EU) households, heating and sanitary hot water account for $79 \%$ of the total final energy use (European Commission, 2017.). Hence, one of the most important targets of the EU is to improve the efficiency of household heating and cooling systems in order to reduce the energy consumption and the emission of greenhouse gases. In this context, heat pumps are an energy-efficient technology for heating and sanitary hot water production. This technology can be an alternative to conventional boilers, which use fossil fuels. According to the European Directive 2009/28/CE, the energy captured by heat pumps can be considered energy from renewable sources if the heat pump systems have an estimated average seasonal performance factor (SPF) higher than a reference value (2.5), which it is feasible to achieve in many of the heat pump applications currently used.

In winter months, when heating demand is higher, heat pumps work with large temperature differences between evaporation and condensation, especially in countries with very low ambient temperatures. Under these conditions, systems working with single-stage vapor compression cycles have reduced efficiency and capacity, mainly due to the limitations of the compression process. At a high-pressure ratio, the discharge temperature of the compressor increases and the volumetric efficiency decreases significantly. Moreover, Carnot and compressor efficiencies decrease dramatically, which reduces the advantage of heat pump systems compared with conventional boilers, which do not show this degradation at low temperatures. In this context, two-stage cycles with vapor-injection have proven to be effective in extending the system operating envelope and improving the performance of heat pumps and refrigeration systems, especially when they work under extreme conditions.

The two-stage compression with vapor-injection comprises the injection of vapor refrigerant into the intermediate location of the compression process. This technique presents several advantages, such as improving the capacity and COP working in harsh climates, reducing the compressor discharge temperature compared to a conventional single-stage cycle, and the system capacity can be varied by controlling the refrigerant injection mass flow rate, which allows some energy savings by avoiding the intermittent operation of the compressor (Xu et al., 2011).

The most common vapor-injection configurations used in two-stage vapor compression systems are vapor-injection with a flash tank and vapor-injection with an economizer (internal heat exchanger). Fig. 1 shows a general schematic of the two-stage vapor compression cycle and the P-h diagrams of the flash tank and economizer configurations.

In the cycle with a flash tank, the refrigerant is expanded to an intermediate pressure, and then the liquid and vapor phases of the refrigerant are separated in the flash tank. The vapor refrigerant is injected into the intermediate stage of compression, while the liquid portion is expanded to the evaporating pressure. In the cycle with an economizer, a portion of the refrigerant is extracted to 
the condenser outlet and is expanded to an intermediate pressure. This portion of the refrigerant is vaporized in the economizer by heat exchange with the rest of the refrigerant, and then it is injected into the intermediate stage of compression. In both cycle configurations, the injection mass flow rate is not allowed to expand to the evaporator pressure; hence, the compression work of this portion of the refrigerant is lower, which results in a COP improvement (Domanski, 1995).

a)

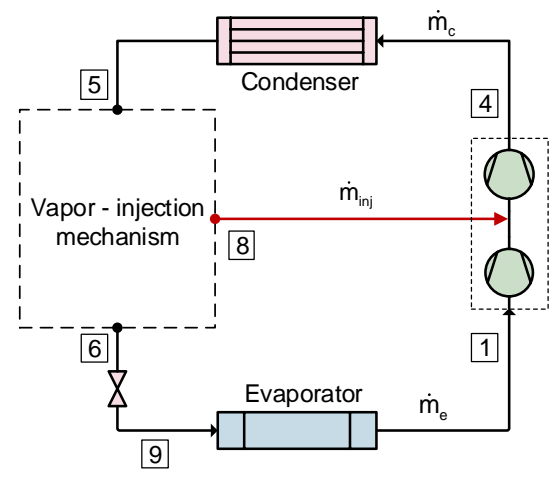

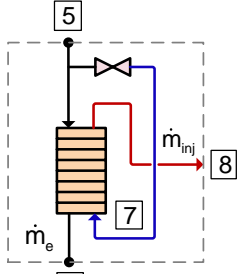

6 Vapor-injection with Economizer

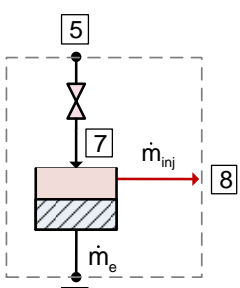

6

Vapor-injection

Flash Tank

b)

c)

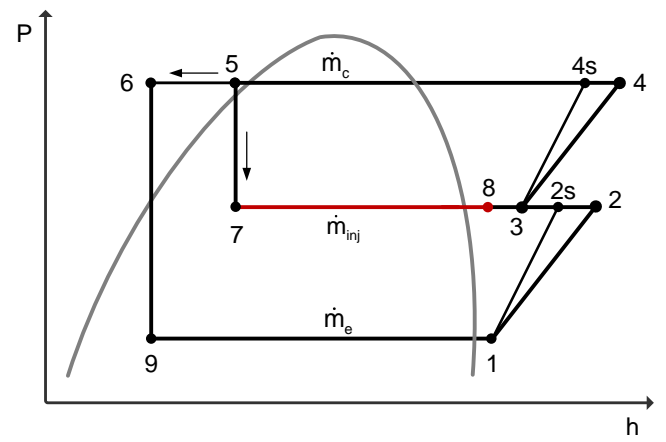

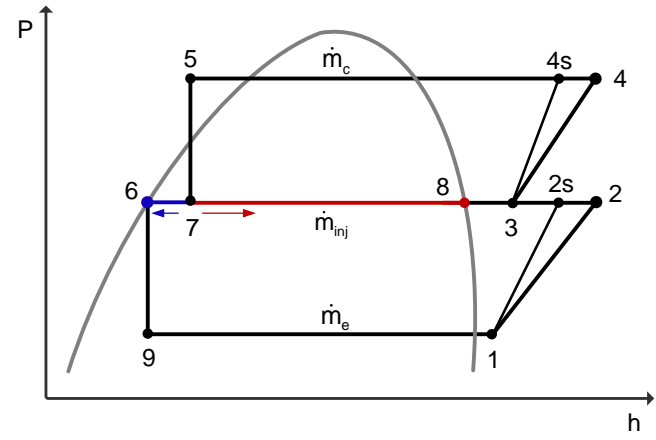

Fig. 1. Two-stage vapor compression cycle with vapor-injection. a) A general schematic of the two-stage cycles. b) P-h diagram of the economizer cycle. c) P-h diagram of the flash tank cycle.

The introduction of new components makes two-stage cycles with vapor-injection more difficult to analyze and design compared with single-stage cycles. Questions about the optimal intermediate pressure, correct sizing of the new components (economizer, two-stage compressor, flash tank, etc.) and control strategies are posed and these need to be understood in order to design new heating equipment using these cycles. Research on these questions has been conducted only in relatively recent years, although two-stage technology has been known from the refrigeration science foundation years. The reason is that, in the past, two-stage technology was used mainly in the sector of industrial refrigeration and the main purpose was to limit the discharge temperature (mainly in ammonia systems), while its temperature levels are very different from those in the domestic heating sector.

A number of experimental studies have been carried out in order to answer the new questions posed by the use of two-stage cycles in this application (Bertsch and Groll, 2008; Heo et al., 2012; 
Ma et al., 2003; Ma and Zhao, 2008; Torrella et al., 2009; Wang et al., 2009a; Xu et al., 2013). As a summary of the experimental works presented, the researchers were focused on demonstrating the benefits of two-stage cycles with vapor-injection (economizer or flash tank type) over the single-stage in terms of operating range, heating, and COP improvements. The researchers also investigated some aspects of the unit control. Nevertheless, there has not yet been any experimental analysis of the optimum two-stage cycle parameters or the influence of the components selection (compressor displacement and economizer area mainly) on the cycle performance.

Several theoretical works have addressed the optimal parameters of two-stage cycles. There are models in the literature that try to optimize given units, such as the works of Bertsch and Groll (2008), Wang et al. (2009b) and Li and Yu (2016). Bertsch and Groll studied the performance of different two-stage cycles at different ambient temperatures, Wang et al. investigated the effect of vapor-injection in a two-stage R-22 cycle using a model with distributed parameters in the heat exchangers, and Liu and Yu studied the optimum allocation of condenser and evaporator areas for a two-stage flash tank cycle working with the refrigerants R-22, R-290, and R-32.

Redón et al. (2014) analyzed the influence of the design parameters and injection conditions of two-stage cycles for the flash tank and economizer configurations. The analysis was performed using four refrigerants, R22, R407C, R290, and R32. The displacement ratio $\left(D_{R}\right)$ of the compressors was optimized in terms of COP in ideal conditions for both injection systems. They used a simple economizer model, which considers a fixed UA value.

Other models found in the literature have the objective of solving general problems for two-stage cycles, as they are not focused on a particular cycle design.

Domanski (1995) performs an analysis of a two-stage cycle with flash tank using a vapor-injection compressor for 38 different refrigerants, reaching a general expression for the optimal intermediate pressure that will be discussed later.

Torrella et al. (2011) described a general methodology to study 5 different two-stage cycles and applied this methodology for refrigeration cycles working with R-404A and R-717 (ammonia). However, their results are given fixing the subcooler effectiveness parameter $\varepsilon$ (Eq. (9)) at $80 \%$, and the intermediate pressure as the geometrical mean of evaporation and condensation pressure, so only a qualitative and particular comparison is made and no optimization is done for the system. Jiang et al. (2015) follow the idea of the previous author to build a general model, in this case applied for heat pump cycles working with R-410A with rolling piston compressors. The model depends on subcooler effectiveness parameter $\varepsilon$ and the outlet enthalpy of the injection mechanism. They made studies of the influence of the parameters on a given cycle working with a particular model of a two-stage variable speed rotary compressor.

Different authors focused their research on the determination of the optimal intermediate pressure. Torrella et al. (2009) summarized several equations for estimating the optimal intermediate 
pressure or the optimal intermediate temperature (dew point) in two-stage vapor compression cycles. Table 1 lists some of the expressions found.

Table 1 Equations for optimum intermediate pressure $\left(\mathrm{T}_{\mathrm{int}, \mathrm{d}}\right)$ found in the literature.

\begin{tabular}{|c|c|c|c|}
\hline Reference & Expression & Refrigerants & Eq. \\
\hline $\begin{array}{l}\text { Behringer } \\
(1928)\end{array}$ & 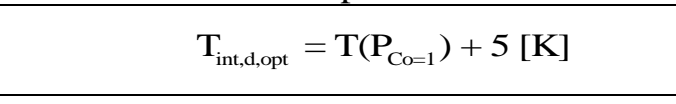 & $\mathrm{R}-717$ & (1) \\
\hline Rasi (1955) & $\mathrm{T}_{\mathrm{int}, \mathrm{d}, \mathrm{opt}}=0.4 \mathrm{~T}_{\mathrm{c}}+0.6 \mathrm{~T}_{\mathrm{e}}+3$ & $\begin{array}{l}\mathrm{R}-12, \mathrm{R}-717 \text {, } \\
\text { methyl chloride }\end{array}$ & (2) \\
\hline $\begin{array}{l}\text { Czaplinski } \\
(1959)\end{array}$ & $\mathrm{T}_{\mathrm{int}, \mathrm{d}, \mathrm{opt}}=\sqrt{\mathrm{T}_{\mathrm{c}} \times \mathrm{T}_{\mathrm{e}}}$ & - & (3) \\
\hline $\begin{array}{l}\text { Baumann and } \\
\text { Blass (1961) }\end{array}$ & $\mathrm{P}_{\mathrm{int,opt}}=\sqrt{\mathrm{P}_{\mathrm{c}} \times \mathrm{P}_{\mathrm{e}}}$ & - & (4) \\
\hline $\begin{array}{l}\text { De Lepeleire } \\
(1973)\end{array}$ & $\mathrm{P}_{\mathrm{int}, \mathrm{opt}}=\sqrt{\mathrm{P}_{\mathrm{c}} \times \mathrm{P}_{\mathrm{e}}}+0.35[\mathrm{bar}]$ & $\mathrm{R}-22$ & $(5)$ \\
\hline $\begin{array}{l}\text { Domanski } \\
(1995)\end{array}$ & $\begin{array}{l}\theta=\frac{\mathrm{T}_{\mathrm{int,d}}-\mathrm{T}_{\mathrm{e}}}{\mathrm{T}_{\mathrm{c}}-\mathrm{T}_{\mathrm{e}}} \approx 0.5 \\
\mathrm{~T}_{\text {int,d,opt }}=0.5\left(\mathrm{~T}_{\mathrm{c}}+\mathrm{T}_{\mathrm{e}}\right)\end{array}$ & $\begin{array}{l}\text { R-22, R-32, R- } \\
\text { 134a, R-290, R- } \\
\text { 717, R-600a, .. }\end{array}$ & $\begin{array}{l}\text { (6) } \\
\text { (7) }\end{array}$ \\
\hline $\begin{array}{l}\text { Jiang et al. } \\
\text { (2016) }\end{array}$ & $\begin{array}{c}\mathrm{T}_{\mathrm{int}, \mathrm{d}, \mathrm{opt}}=0.5\left(\mathrm{~T}_{\mathrm{c}}+\mathrm{T}_{\mathrm{e}}\right)+\left(\mathrm{T}_{\mathrm{c}}-\mathrm{T}_{\mathrm{e}}\right) f_{1}\left(\varepsilon, \mathrm{T}_{\mathrm{c}, \mathrm{r}}, \mathrm{T}_{\mathrm{e}, \mathrm{r}}\right) \\
\varepsilon=\frac{\mathrm{h}_{5}-\mathrm{h}_{9}}{\mathrm{~h}_{5}-\mathrm{h}_{\mathrm{inj}, \mathrm{b}}}\end{array}$ & R-22, R-717 & $\begin{array}{l}\text { (8) } \\
(9)\end{array}$ \\
\hline
\end{tabular}

One of the most relevant and general works is the one performed by Domanski (1995). The author studied 38 fluids with different molar weights based on the flash tank cycle. In the two expansion devices of the cycle, zero subcooling was used. It was found that the optimum intermediate temperatures are fairly uniform for the fluids considered and can be well approximated by using the mean temperature between the condenser and evaporator (Eq. (7)). The correlation proposed by Domanski does not take into account the dependence of the subcooling at the condenser outlet on the optimum point of the system. This result was confirmed by independent researchers Zubair et al. (1996) and Ouadha et al. (2005).

Jiang et al. (2016) used their cited model in order to adapt the equation proposed by Domanski for economizer cycles, introducing the parameter $\varepsilon$ defined in Eq. (9). They presented a correlation for the refrigerants R-22 and R-717 (Eq. (8)).

In all of these previous studies, the optimum intermediate conditions of the cycle have been analyzed in terms of the refrigerant-side conditions, and the application conditions (secondary fluid side) have been omitted. Indeed, the optimum of the cycle was obtained as a function of the evaporating and condensing temperatures. However, in a real system, the condensing temperature is not fixed and is determined by the temperature level and the temperature lift of the secondary fluid, which is the one defined by the application. The subcooling is a critical variable that depends 
directly on the application conditions. Redón et al. (2014) introduced an analysis of the variation of the system variables as a function of subcooling for the optimum condition. As the subcooling increases, the intermediate pressure decreases, as do the injection flow and the compressor power input. Hence, the performance of the system improves when the subcooling increases. Pitarch et al. (2017) demonstrated that, for single-stage cycles, there is an optimum subcooling for each application. Consequently, not only the condensing temperature is important in the optimization of the two-stage cycles with vapor-injection, but also the subcooling. In this context, the subcooling has to be included in the correlation of the optimum intermediate pressure for this kind of cycle. The only study found in the literature that addresses this point is the one by Arora and Kaushik (2010) that studied the influence of 5K subcooling variation at the condenser for a twostage system with flash tank working with refrigerants R-22, R-410A and R-717. Studies were carried out for an evaporation temperature of $-30{ }^{\circ} \mathrm{C}$ and they reported a big subcooling influence but did not develop a correlation using this parameter.

Up to this point, the state of the art about experimental and theoretical studies of two-stage cycles with vapor-injection has been addressed, and several gaps have been found in the study of this kind of cycle. Based on this literature review, the current paper thus addresses a thermodynamic study of the two-stage cycles with vapor-injection, where the key parameters of the cycle design are identified, and the influence of these parameters on the heating COP is analyzed (section 2). The optimum intermediate conditions of the cycle are evaluated for several refrigerants using a general model of the cycle (sub-section 3.1). Then, the optimum intermediate pressure was studied for two configurations, flash tank, and economizer. Based on the optimization results, a correlation is proposed in order to estimate the optimum intermediate pressure, taking into account the temperature lift in the secondary fluid imposed by the application (sub-section 3.2). The correlation proposed uses cycle subcooling as an input, which is a novelty from the current correlations proposed in the literature, and an optimum subcooling control strategy is proposed. Finally, focusing on the cycle with an economizer, the influence of the size of the system components (compressors, condenser, and economizer) on the heating COP is studied (subsection 3.3). A two-zone heat exchanger model for the economizer is implemented and included in a general model of the two-stage cycle with vapor-injection. Adding the economizer model, the heat exchange area (number of heat exchanger plates) can be fixed in order to study the behavior of the cycle with different economizer sizes working with several intermediate conditions for a given operating point.

\section{METHODOLOGY}

\section{System of equations}


In order to establish the optimum parameters for the two-stage cycles with vapor-injection, a cycle thermodynamic model is implemented. Independently of the compressor technology, the compression mechanism is modeled as a black box with all components included in the same shell and driven by the same electric motor. In this case, the first compression and injection mixing take place inside the compressor and therefore the concept of compressor efficiency includes irreversibilities incurred in this process; so refrigerant points 2 and 3 plotted in Fig. 1 are auxiliary points in order to establish the appropriate relationships between inlet and outlet compressor variables.

The compressor efficiency is defined by Eq. (10), where point 3 is obtained from Eq. (11), assuming perfect adiabatic mixing after the first isentropic compression.

$$
\begin{aligned}
& \eta_{c}=\frac{\dot{\mathrm{m}}_{\mathrm{e}}\left(\mathrm{h}_{2 \mathrm{~s}}-\mathrm{h}_{1}\right)+\dot{\mathrm{m}}_{\mathrm{c}}\left(\mathrm{h}_{4 \mathrm{~s}}-\mathrm{h}_{3}\right)}{\dot{\mathrm{E}}} \\
& \dot{\mathrm{m}}_{\mathrm{c}} \mathrm{h}_{3}=\dot{\mathrm{m}}_{\mathrm{e}} \mathrm{h}_{2 \mathrm{~s}}+\dot{\mathrm{m}}_{\mathrm{inj}} \mathrm{h}_{8}
\end{aligned}
$$

The unknowns of the problem are the thermodynamic properties (pressure and enthalpy) of all the cycle points shown in Fig. 1 except points 2 and 3 ( 7 total points). Additional unknowns are the mass flow rates flowing through the evaporator, condenser, and the injection mass flow rate. The pressure levels of the system are calculated as the saturation pressure of the dew temperatures at the evaporator, condenser and injection. Introducing the assumption of null pressure drop in the lines and heat exchangers of the system, 3 additional equations are stated in order to establish all the cycle pressures. Also, introducing the assumption of isenthalpic expansion in the valves, 2 more equations are stated between the enthalpies of points 5-7 and 6-9 (see Fig. 1).

With the input parameters of superheat and subcooling, the temperatures of points 1 and 5 can be calculated and therefore their enthalpies. Additionally, the following balance can be stated in the injection system:

$$
\begin{aligned}
& \dot{\mathrm{m}}_{\mathrm{c}} \mathrm{h}_{5}=\dot{\mathrm{m}}_{\mathrm{e}} \mathrm{h}_{6}+\dot{\mathrm{m}}_{\mathrm{inj}} \mathrm{h}_{8} \\
& \dot{\mathrm{m}}_{\mathrm{c}}=\dot{\mathrm{m}}_{\mathrm{e}}+\dot{\mathrm{m}}_{\mathrm{inj}}
\end{aligned}
$$

Finally, the evaporator mass flow rate and outlet compressor enthalpy can be calculated as follows:

$$
\begin{aligned}
& \dot{\mathrm{m}}_{\mathrm{e}}=\rho\left(\mathrm{P}_{1}, \mathrm{~h}_{1}\right) \dot{\mathrm{V}} \eta_{v} \\
& \dot{\mathrm{m}}_{\mathrm{c}} \mathrm{h}_{4}=\frac{\dot{\mathrm{m}}_{\mathrm{e}}\left(\mathrm{h}_{2 \mathrm{~s}}-\mathrm{h}_{1}\right)+\dot{\mathrm{m}}_{\mathrm{c}}\left(\mathrm{h}_{4 \mathrm{~s}}-\mathrm{h}_{3}\right)}{\eta_{c}}+\dot{\mathrm{m}}_{\mathrm{e}} \mathrm{h}_{1}+\dot{\mathrm{m}}_{\mathrm{inj}} \mathrm{h}_{8}-\dot{\mathrm{Q}}_{\text {loss }}
\end{aligned}
$$


where $\dot{\mathrm{Q}}_{\text {loss }}$ is the heat loss in the compressor to the ambient.

The problem stated has 17 unknowns; 14 thermodynamic properties (pressure and enthalpy) for the 7 system points and 3 mass flow rates (evaporator, condenser, and injection). The equations posed are 3 for the pressure levels, 3 for pressure equalities, 2 for isenthalpic expansions, 2 equations involving cycle superheat and subcooling, 2 equations for injection mechanism balance (Eq. (12) and Eq. (13)) and 2 equations for compressor performance (Eq. (14) and Eq. (15)). The parameters used in the model are the dew evaporation and condensation temperature $\left(T_{e, d}\right.$, $\mathrm{T}_{\mathrm{c}, \mathrm{d}}$ ), cycle superheat and subcooling $(\mathrm{SH}, \mathrm{SC}$ ) and compressor volumetric and energetic efficiency $\left(\eta_{\mathrm{v}}, \eta_{\mathrm{c}}\right)$. The output variables calculated by the model are heating capacity, compressor power input and heating COP.

The total number of equations is 19 , so the system has three degrees of freedom. The proposed parameters to solve the system of equations are the intermediate pressure, $\mathrm{P}_{\text {int }}$, the injection ratio $\mathrm{X}_{\text {inj }}\left(\right.$ defined as $\mathrm{X}_{\mathrm{inj}}=\frac{\dot{\mathrm{m}}_{\mathrm{inj}}}{\dot{\mathrm{m}}_{\mathrm{c}}}$ ), and the intermediate superheat at point $8, \mathrm{SH}_{\mathrm{int}}$.

As pointed out by Redón et al. (2014), the injection mechanism type can add a number of constraints. In the case of the flash tank configuration, two additional constraints are added as points 8 and 6 must be in a saturated state. The consequence is that only one parameter can vary, and is normally fixed by the selection of the injection compressor, which poses a constraint for the injection mass flow rate, having the intermediate pressure as a result of the balance.

Using the economizer configuration makes the system more flexible as it can work with three independent degrees of freedom (intermediate pressure, injection mass flow rate and injection superheat), bounded by the limits of the second law that in this particular case can be stated as:

$$
\begin{aligned}
& \mathrm{DT}_{\mathrm{d}}=\mathrm{T}_{5}-\mathrm{T}_{8} \geq 0 \\
& \mathrm{DT}_{\mathrm{b}}=\mathrm{T}_{6}-\mathrm{T}_{\mathrm{int,b}} \geq 0
\end{aligned}
$$

It is noted that using a flash tank configuration always makes $\mathrm{DT}_{\mathrm{b}}=0$.

The model presented has been implemented in EES software (F-Chart Software, 2017) and it is capable of solving the given equations with given parameters and restrictions for any common refrigerant.

The model has been used to answer the questions posed in the introduction, applied mainly to heating applications. The refrigerants selected for the study are R-22, R-407C, R-410A, R-134a, R-32, R-290, and R-1234yf, which are a selection of refrigerants used in the past (R-22), nowadays (R-407C, R-410A, R-134a) and proposed future alternatives (R-32, R-290, and R1234yf).

The compressor efficiencies are set in all the studies as unity and null heat loss is considered. 
Compressor and economizer models are used to study the influence of their design on the cycle performance. In the compressor case, the given constant compressor efficiencies are enough to include the influence of the displacement ratio. However, for the case of the economizer, there is no simple expression to represent its behavior in the system, and a commonly used approach in the analysis of heat exchangers is to consider a fixed UA and using an $\varepsilon$-Ntu approach that is not valid in this application.

In this context, a two-zone model of a heat exchanger is implemented to determine the economizer's behavior in the cycle. The optimum intermediate conditions of an economizer cycle and the influence of the economizer size on the COP are studied when the system operates at working points different from the design point. For that, a brazed plate heat exchanger is modeled in detail and is incorporated into the general model of the two-stage cycle.

Generally, brazed plate heat exchangers are used as economizers in two-stage cycles with vaporinjection. The heat exchanger is modeled considering two zones of heat transfer in the cold stream, the two-phase zone (I) and the vapor-liquid zone (II), and one zone in the hot stream. The flow arrangement into the heat exchanger is counter-flow. Fig. 2 illustrates the temperature profile in the heat exchanger considering the two zones of the heat transfer.

HEAT EXCHANGER
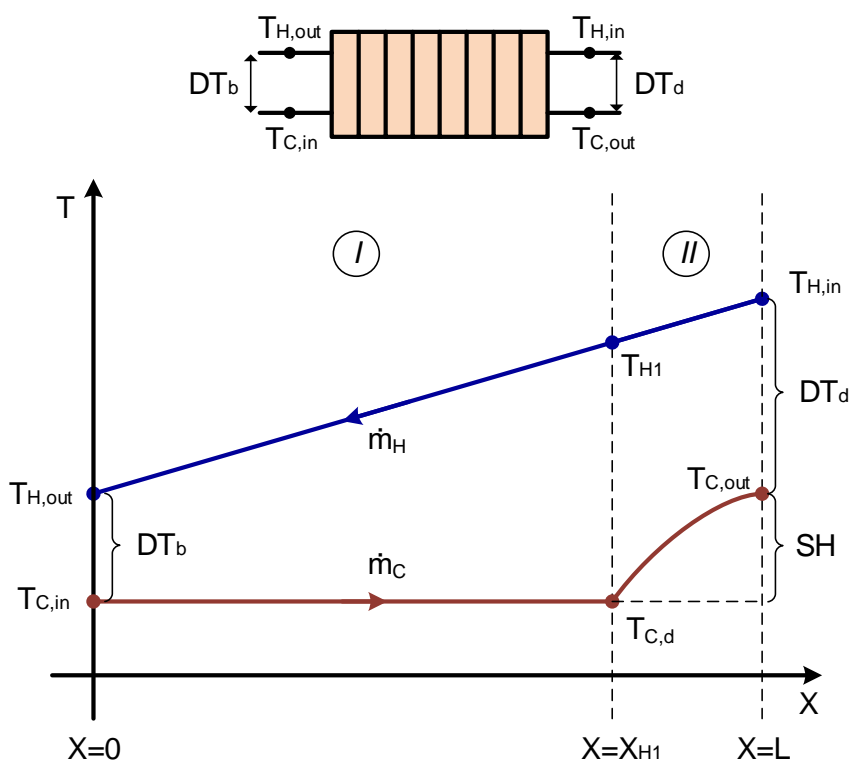

Fig. 2. Temperature profile in the heat exchanger considering two zones of heat transfer.

The heat exchanger model is based on the $\varepsilon$-Ntu method for each zone. This model is able to calculate the heat exchanged, given some dimensional features of the heat exchanger such as the number of plates and the plate geometry. The heat transfer coefficients are estimated using the correlation of Kumar (1984) for single-phase flow and the correlation of Cooper (1984) for twophase flow (Ayub, 2003; Nellis and Klein, 2009). All the models have been implemented using 
EES software (F-Chart Software, 2017), and the thermophysical properties of the refrigerants at the different points are calculated with the NIST REFPROP database (Lemmon et al., 2010).

\section{RESULTS AND DISCUSSION}

\subsection{Optimization of the two-stage cycle with vapor-injection}

Cycle optimization has been realized using the conjugate gradient method in multi-dimensions (Press et al., 2007). Table 2 shows the optimization results of the ideal two-stage cycle with vaporinjection.

Table 2 Optimization results of the intermediate conditions for the ideal two-stage cycle with vapor-injection. Working point $\left(\mathrm{T}_{\mathrm{e}}=-15^{\circ} \mathrm{C}, \mathrm{T}_{\mathrm{c}}=60{ }^{\circ} \mathrm{C}, \mathrm{SH}=5 \mathrm{~K}, \mathrm{SC}=5 \mathrm{~K}\right)$.

\begin{tabular}{|l|c|c|c|c|c|c|c|c|c|c|c|c|c|c|c|}
\hline REF & $\begin{array}{c}\mathrm{X}_{\text {inj }} \\
(-)\end{array}$ & $\begin{array}{c}\mathrm{SH}_{\text {int }} \\
(\mathrm{K})\end{array}$ & $\begin{array}{c}\mathrm{P}_{\text {int }} \\
(\mathrm{kPa})\end{array}$ & $\begin{array}{c}\mathrm{DT}_{\mathrm{b}} \\
(\mathrm{K})\end{array}$ & $\begin{array}{c}\mathrm{DT}_{\mathrm{d}} \\
(\mathrm{K})\end{array}$ & $\begin{array}{c}\mathrm{C}_{\mathrm{o}} \\
(-)\end{array}$ & $\begin{array}{c}\mathrm{T}_{\text {int,d }} \\
\left({ }^{\circ} \mathrm{C}\right)\end{array}$ & $\begin{array}{c}\mathrm{D}_{\mathrm{R}} \\
(-)\end{array}$ & $\begin{array}{c}\mathrm{T}_{\mathrm{dis}} \\
\left({ }^{\circ} \mathrm{C}\right)\end{array}$ & $\begin{array}{c}\mathrm{COPh} \\
(-)\end{array}$ & $\begin{array}{c}\theta \\
(-)\end{array}$ & $\begin{array}{c}\mathrm{DQ}_{\mathrm{h}} \\
(\%)\end{array}$ & $\begin{array}{c}\mathrm{DCOP}_{\mathrm{h}} \\
(\%)\end{array}$ & $\begin{array}{c}\Delta \mathrm{COP}_{\mathrm{h}, \text { opt }} \\
\left(\mathrm{SH}_{\text {int }}=0 \mathrm{~K}\right) \\
(\%)\end{array}$ & $\begin{array}{c}\Delta \mathrm{COP}_{\mathrm{h}, \text { opt }} \\
\left(\mathrm{SH}_{\text {int }}=5 \mathrm{~K}\right) \\
(\%)\end{array}$ \\
\hline R-407C & 0.24 & 29.14 & 925.16 & 0.00 & 0.00 & 1.13 & 21.69 & 0.42 & 89.44 & 3.73 & 0.49 & 34.70 & 16.30 & 0.16 & 0.13 \\
\hline R-22 & 0.23 & 0.00 & 950.46 & 0.00 & 33.45 & 1.12 & 21.55 & 0.46 & 93.20 & 3.80 & 0.48 & 27.20 & 12.80 & 0.00 & 0.03 \\
\hline R-290 & 0.24 & 34.46 & 848.67 & 0.00 & 0.00 & 1.08 & 20.55 & 0.50 & 77.98 & 3.79 & 0.47 & 37.30 & 17.40 & 0.48 & 0.40 \\
\hline R-410A & 0.26 & 31.99 & 1562.19 & 0.00 & 0.00 & 1.15 & 22.91 & 0.47 & 99.85 & 3.58 & 0.51 & 37.20 & 17.50 & 0.17 & 0.14 \\
\hline R-1234yf & 0.24 & 34.67 & 578.00 & 0.00 & 0.00 & 1.10 & 20.33 & 0.41 & 78.59 & 3.84 & 0.47 & 36.30 & 16.90 & 0.36 & 0.31 \\
\hline
\end{tabular}

The most interesting conclusion is that for all the refrigerants calculated, the optimum is reached when the temperature approach between the outlet hot stream and inlet cold stream in the injection mechanism is null, $\mathrm{DT}_{\mathrm{b}}=0$. This condition is always reached in the flash tank configuration and in the case of the economizer configuration is the consequence of using an infinite heat transfer area.

The variable $\mathrm{DT}_{\mathrm{d}}$ gives the temperature approach at the other side of the injection mechanism between the inlet hot stream and outlet cold stream. Analyzing the $\mathrm{DT}_{\mathrm{d}}$ values, two groups of refrigerants are identified. The first group is composed of R-22 and R-32. These refrigerants reach the optimum when the injection superheat is zero $\left(\mathrm{DT}_{\mathrm{d}}>0\right)$, which is the condition imposed by the flash tank configuration. The rest of the analyzed refrigerants make up the second group of refrigerants. They reach the optimum when working with a high injection superheat $\left(D_{d}=0\right)$, which can be reached by an infinite heat transfer area economizer. These conclusions confirm the results obtained by previous works (Redón et al., 2014). 
A new definition is included in the comparison, the variable $\mathrm{C}_{0}$, which is the ratio between the actual intermediate pressure and the geometric mean of pressures:

$$
\mathrm{C}_{\mathrm{o}}=\frac{\mathrm{P}_{\mathrm{int,d}}}{\sqrt{\mathrm{P}_{\mathrm{e}, \mathrm{d}} \mathrm{P}_{\mathrm{c}, \mathrm{d}}}}
$$

The values of the geometric mean of pressures are commonly used and cited in design practice, although this is only valid for calculating the minimum power input in an ideal gas with external intercooling between stages. The optimum $\mathrm{C}_{\mathrm{o}}$ values are always greater than unity for all refrigerants calculated, so the optimum intermediate pressure is always higher than the geometric mean.

Variable $\theta$, used by Domanski (1995) in his correlation, is also reported in the table and is defined in Eq. (6). $\theta$ values are close to 0.5 , which is the value reported by Domanski as an approximation for the calculation of the optimum intermediate pressure.

The required displacement ratio between the second and first stage of compression, $D_{R}$, gives a first idea about the compressor design (taking into account the compressor model approximations used). The results show that the optimum displacement ratio will be between 0.41 and 0.5 for all refrigerants considered.

The role of using a flash tank or economizer as the injection mechanism is well understood with the results presented. A unique parameter is allowed to vary when using a flash tank configuration, the intermediate pressure. In the case of R-22 and R-32, using a flash tank with a two-stage compressor with displacement ratios of 0.46 and 0.47 respectively allows working at the optimum intermediate pressure. For all the other refrigerants, the null superheat imposed by the flash tank means that the optimum will never be reached. The second to last column shows the COP difference between the optimum and the value reached with null intermediate superheat. The differences are quite low, as the maximum value is $1.02 \%$ in the case of R-1234yf, so using the flash tank configuration with the right compressor design makes the system works near the optimum for the working condition established.

The economizer configuration allows more flexibility of control and design, as three independent parameters can be varied in the cycle with its use. The results show that the optimum can only be reached when the economizer has an infinite heat transfer area, a theoretical condition that can never be accomplished in practice. Depending on the refrigerant, the superheat value controlled by the expansion device needs to be null or very high. Normally, the value controlled by the expansion device is around $5 \mathrm{~K}$ in order to avoid control instabilities and to maintain lower discharge temperatures. The last column of Table 2 shows the COP differences between the optimum and the system working with $5 \mathrm{~K}$ intermediate superheat. The differences are quite low 
and the differences when using a flash tank (zero superheat) are negligible. The results suggest that intermediate superheat has little impact on the cycle efficiency.

Fig. 3 shows the propane COP variations at $5 \mathrm{~K}$ of intermediate superheat at different values of the normalized injection ratio and intermediate dew temperature defined as:

$$
\begin{aligned}
& X_{\text {inj }}^{\prime}=\frac{X_{\text {inj }}}{X_{\text {inj,max }}} \\
& T_{\text {int,d }}^{\prime}=\frac{T_{\text {int,d }}-T_{\text {int,d,min }}}{T_{\text {int,d,max }}-T_{\text {int,d,min }}}
\end{aligned}
$$

where the minimum intermediate temperature is $T_{i n t, d, m i n}=T_{e, d}$. The maximum intermediate temperature is limited by the condition $\mathrm{DT}_{\mathrm{d}}=0$, so $\mathrm{T}_{\mathrm{int}, \mathrm{d}, \max }=\left(\mathrm{T}_{\mathrm{c}, \mathrm{d}}-\mathrm{SC}-\mathrm{SH}_{\mathrm{int}}\right)$. The maximum injection ratio is obtained when the following conditions are fulfilled: $\mathrm{T}_{\mathrm{int}, \mathrm{d}}=\mathrm{T}_{\mathrm{e}, \mathrm{d}}$ and $\mathrm{DT}_{\mathrm{b}}=0$.

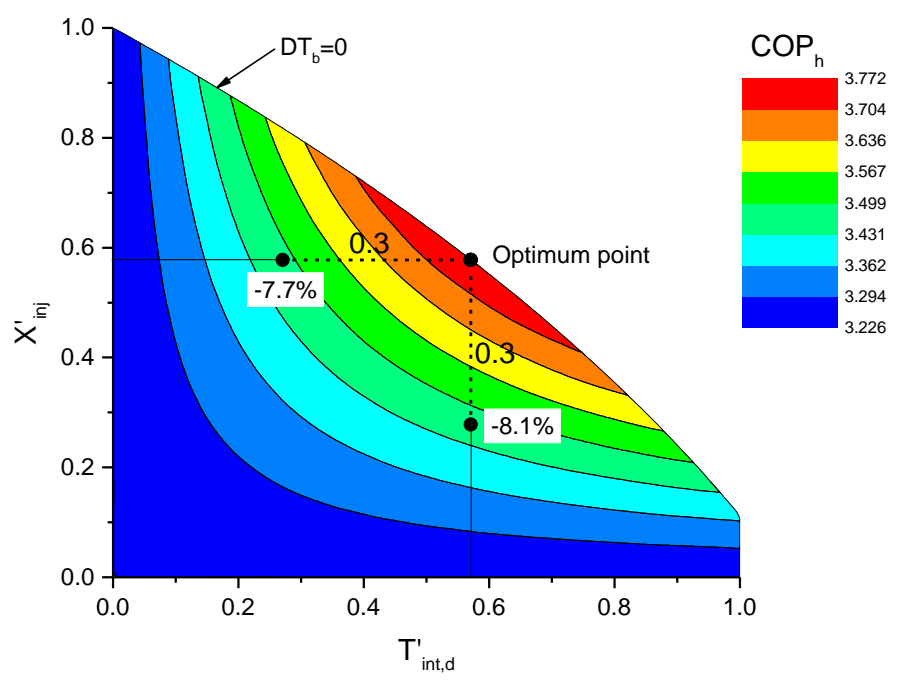

Fig. 3. Contour map of heating $\mathrm{COP}$ as a function of normalized injection ratio and normalized intermediate saturation temperature at the intermediate pressure. Working condition $\left(\mathrm{T}_{\mathrm{e}}=-15^{\circ} \mathrm{C}, \mathrm{T}_{\mathrm{c}}=60{ }^{\circ} \mathrm{C}, \mathrm{SH}=5 \mathrm{~K}, \mathrm{SC}=5 \mathrm{~K}\right.$ and $\left.\mathrm{SH}_{\text {int }}=5 \mathrm{~K}\right)$. Refrigerant $\mathrm{R}-290$.

The optimum COP is 3.77 at $5 \mathrm{~K}$ intermediate superheat, which is $0.4 \%$ lower than the optimum shown in Table 2 obtained with $34.46 \mathrm{~K}$ superheat. Two points are plotted in the figure, varying the injection ratio and intermediate pressure respectively while maintaining the other variable constants. The COP variations with these variables are much higher $(7.7 \%$ and $8.1 \%)$ than those produced by intermediate superheat variations. This behavior is observed for all refrigerants and at different working points, so a first approach to simplify the problem analysis is to consider the influence of the intermediate superheat as negligible compared with the injection ratio and intermediate pressure variations. 
As commented above, all the previous studies about correlations for the optimum intermediate pressure in two-stage cycles with vapor-injection were carried out considering a constant or zero subcooling. Nevertheless, by considering a real system with a temperature lift in the secondary fluid of the condenser $\left(\Delta \mathrm{T}_{\mathrm{w}}\right)$, a water inlet temperature $\left(\mathrm{T}_{\mathrm{w}, \text { in }}\right)$, and by assuming a condenser with an infinite heat transfer area, the optimal $\mathrm{COP}_{\mathrm{h}}$ of the system is obtained for a unique subcooling. According to Pitarch et al. (2017), the optimal subcooling is obtained when the condition of having two pinch points of $0 \mathrm{~K}$ between the refrigerant and secondary fluid takes place at the same time in the condenser of infinite heat transfer area (see the temperature profile of Fig. 4). This condition constitutes another thermodynamic constraint of the cycle, which must be satisfied to optimize the intermediate pressure. Therefore, the optimal intermediate conditions of the twostage vapor compression cycles have to be analyzed in terms of the working conditions and the subcooling.

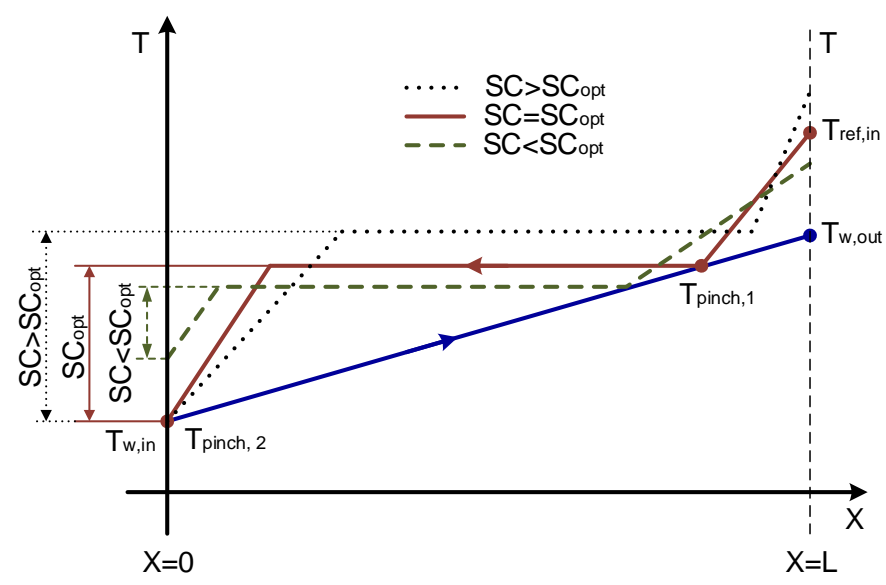

Fig. 4. Temperature profile of the water and refrigerant into condenser with different subcooling.

In order to find an expression that estimates the optimum intermediate pressure as a function of the working conditions and the subcooling, the results of Table 3 show that the approach stated by Domanski (1995) is right, so its correlation is expanded, including the subcooling dependence in the optimum of the cycle, which until now has not been considered in the literature. For this purpose, several simulations of the two cycles (flash tank and economizer) were made, considering a wide range of operating conditions, and for the refrigerants cited in section 2 . The simulations consider evaporating temperatures of $-30{ }^{\circ} \mathrm{C}$ to $15{ }^{\circ} \mathrm{C}$ and condensing temperatures of $30{ }^{\circ} \mathrm{C}$ to $68{ }^{\circ} \mathrm{C}$. For each working condition $\left(\mathrm{T}_{\mathrm{e}}, \mathrm{T}_{\mathrm{c}}\right)$, the subcooling is varied between $[0 \mathrm{~K}-$ $20 \mathrm{~K}$ ]. In all simulations, the superheat at the first-stage compressor inlet was $5 \mathrm{~K}$. For the 
refrigerants R-410A and R-32, the maximum condensing temperature considered for obtaining the correlation was $60{ }^{\circ} \mathrm{C}$ because the higher temperatures are close to the critical temperature.

For the economizer cycle, the injection superheat is fixed to $5 \mathrm{~K}$. This value was chosen because in the majority of systems the intermediate pressure control is performed with a thermostatic expansion valve. This valve needs a minimum superheat to regulate properly; therefore, an intermediate superheat of $5 \mathrm{~K}$ is appropriate for this kind of system. Furthermore, the injection superheat, as shown in the previous section, does not greatly influence the COP of the system, and finally, the inlet temperature of the second-stage compressor should be as low as possible to reduce the discharge temperature of the second compression stage.

The economizer size is fixed by setting the temperature approach in the economizer $\left(T_{6}-T_{7}\right.$ in Fig. 1a). For all operating points, this temperature approach is assumed constant (5 K) (EN 12900, 2014). In order to consider the temperature glide of the zeotropic mixtures, the temperature of point 7 is replaced by the bubble point of the intermediate pressure in the temperature approach, that is, $\mathrm{DT}_{\mathrm{b}}=5 \mathrm{~K}$. By fixing these parameters for each cycle configuration, the intermediate dew point temperature is the only independent variable for optimizing the system.

a)

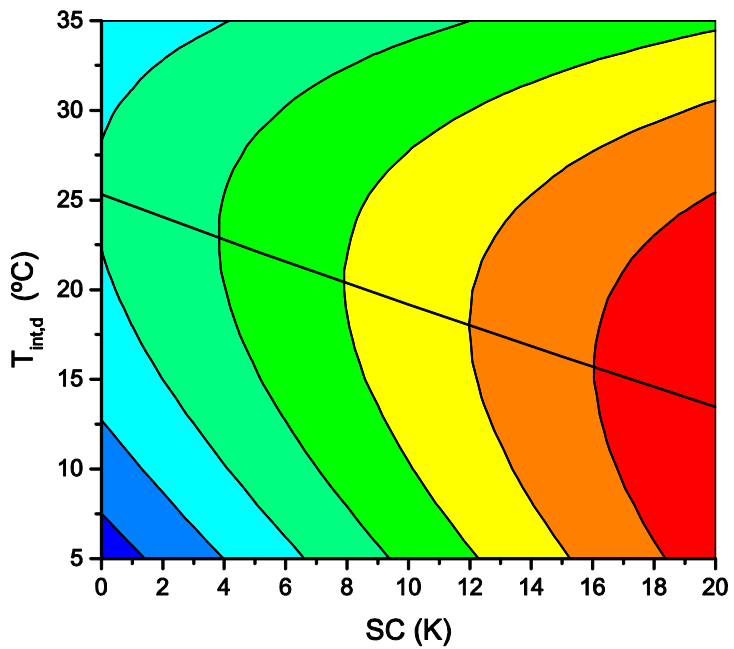

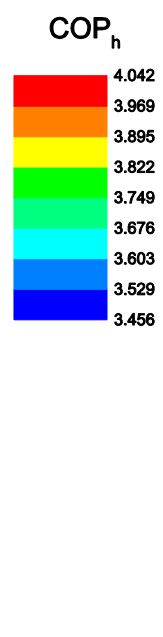

b)

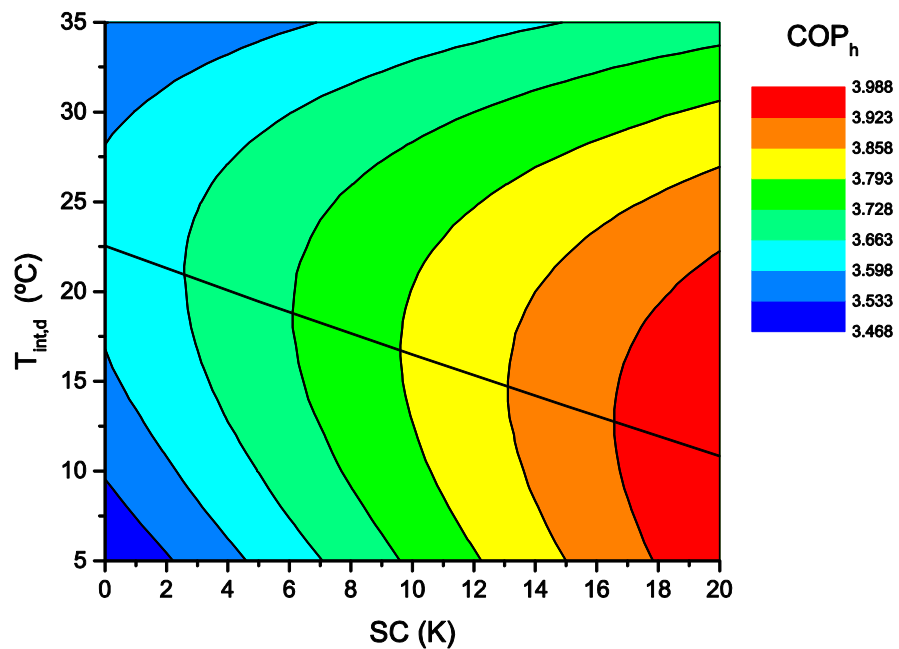

Fig. 5. Subcooling influence on heating $C O P$ and $T_{\text {int,d,opt }}$ of an ideal system. Working point $\left(\mathrm{T}_{\mathrm{e}}=-15^{\circ} \mathrm{C}, \mathrm{T}_{\mathrm{c}}=60{ }^{\circ} \mathrm{C}\right.$, $\mathrm{SH}=5 \mathrm{~K})$ for R-290. a) Flash tank cycle $\left(\mathrm{DT}_{\mathrm{b}}=0\right)$. b) Economizer cycle $\left(\mathrm{DT}_{\mathrm{b}}=5 \mathrm{~K}, \mathrm{SH}_{\mathrm{int}}=5 \mathrm{~K}\right)$.

Fig. 5 shows the influence of the subcooling at the condenser outlet on the heating COP and the optimum intermediate temperature for ideal two-stage cycles with the flash tank and economizer. It can be seen that the optimum intermediate temperature decreases when the subcooling increases for both cycle configurations. The variation of the optimum intermediate temperature as a function of the subcooling is almost linear.

According to the optimization results and based on Eq. (7) proposed by Domanski (1995), a new linear term is added to the mean temperature between the condenser and evaporator in order to include the effect of the subcooling in the optimal intermediate conditions. Hence, the $T_{\text {int,d,opt }}$ can 
be correlated as a function of the subcooling and the evaporating and condensing temperatures through Eq. (21), where $K_{1}$ and $K_{2}$ are 0.5 based on Eq. (7), and $K_{3}$ is obtained by linear regression. The optimum intermediate pressure can be calculated through $\mathrm{T}_{\text {int,d,opt }}$ by using Eq.

$$
\begin{aligned}
& \mathrm{T}_{\text {int,d,opt }}=\mathrm{K}_{1} \mathrm{~T}_{\mathrm{c}}+\mathrm{K}_{2} \mathrm{~T}_{\mathrm{e}}+\mathrm{K}_{3} \mathrm{SC} \\
& \mathrm{P}_{\text {int,opt }}=\mathrm{P}_{\text {sat }}\left(\mathrm{T}=\mathrm{T}_{\text {int, d,opt }}\right)
\end{aligned}
$$

The coefficients $\mathrm{K}_{1}, \mathrm{~K}_{2}$, and $\mathrm{K}_{3}$ of the correlation (21) for the two cycle configurations (flash tank and economizer) are shown in Table 3 , as well as the maximum deviations of the $\mathrm{T}_{\text {int,d,opt }}$ and $\mathrm{P}_{\text {int,opt. }}$

Table 3 Coefficients of the optimum intermediate dew temperature correlation of the twostage cycles with vapor-injection for all studied refrigerants.

\begin{tabular}{|c|c|c|c|c|c|c|}
\hline $\begin{array}{c}\text { Cycle } \\
\text { configuration }\end{array}$ & $\mathbf{K}_{\mathbf{1}}$ & $\mathbf{K}_{\mathbf{2}}$ & $\mathbf{K}_{\mathbf{3}}$ & $\mathbf{R}^{\mathbf{2}}$ & $\begin{array}{c}\text { Max. deviation } \\
\mathbf{T}_{\text {int,d,opt }}[\mathbf{K}]\end{array}$ & $\begin{array}{c}\text { Max. deviation } \\
\mathbf{P}_{\text {int,opt }}[\mathbf{\%}]\end{array}$ \\
\hline Flash tank & 0.5 & 0.5 & -0.458 & 0.9976 & -4.89 & -12.58 \\
\hline Economizer & 0.5 & 0.5 & -0.621 & 0.9979 & -2.94 & -7.76 \\
\hline
\end{tabular}

For the two cycle configurations, the R-square correlation factor (Press et al., 2007) is higher than 0.99. The maximum deviation in the estimation of the $\mathrm{T}_{\text {int,d,opt }}$ is lower than $5 \mathrm{~K}$ for the cycle with a flash tank and lower than $3 \mathrm{~K}$ for the cycle with an economizer. The maximum deviation in the estimation of the $\mathrm{P}_{\text {int,opt }}$ is lower than $13 \%$ for the cycle with a flash tank and lower than $8 \%$ for the cycle with an economizer. These results are satisfactory for the estimation of the optimum intermediate conditions for two-stage vapor-injection systems. It must be noted that the obtained correlation is valid for all the studied refrigerants, and it can be used in the control systems in order to provide a simple way to fix the optimum intermediate pressure.

Fig. 6(a) represents the comparison between the model and correlation results of the intermediate dew point temperature and Fig. 6(b) represents the comparison of the model and correlation results for the optimum intermediate pressure. The two figures show a correct agreement between the model simulation and correlation results. 
a)

Optimum intermediate dew point temperature

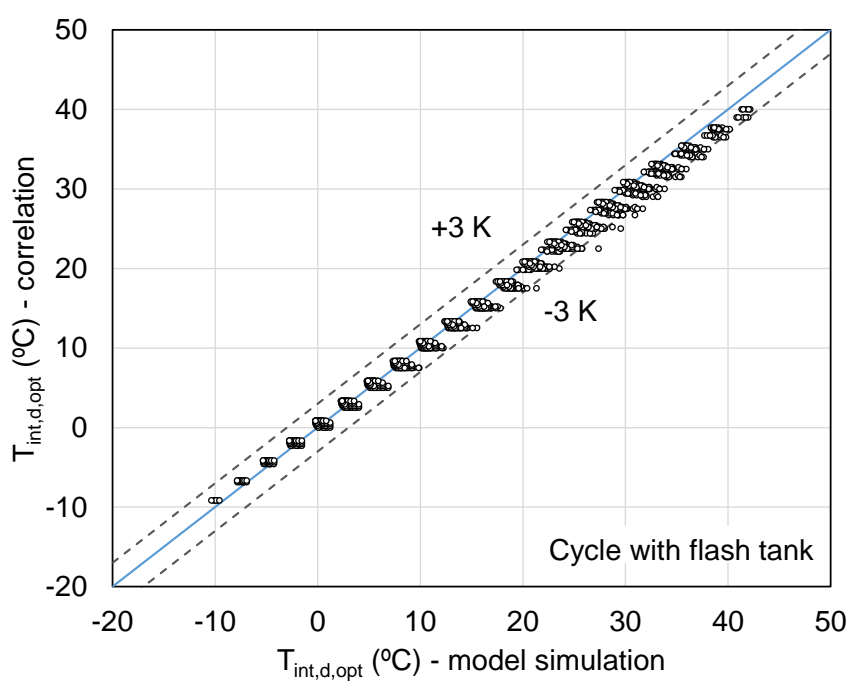

b)

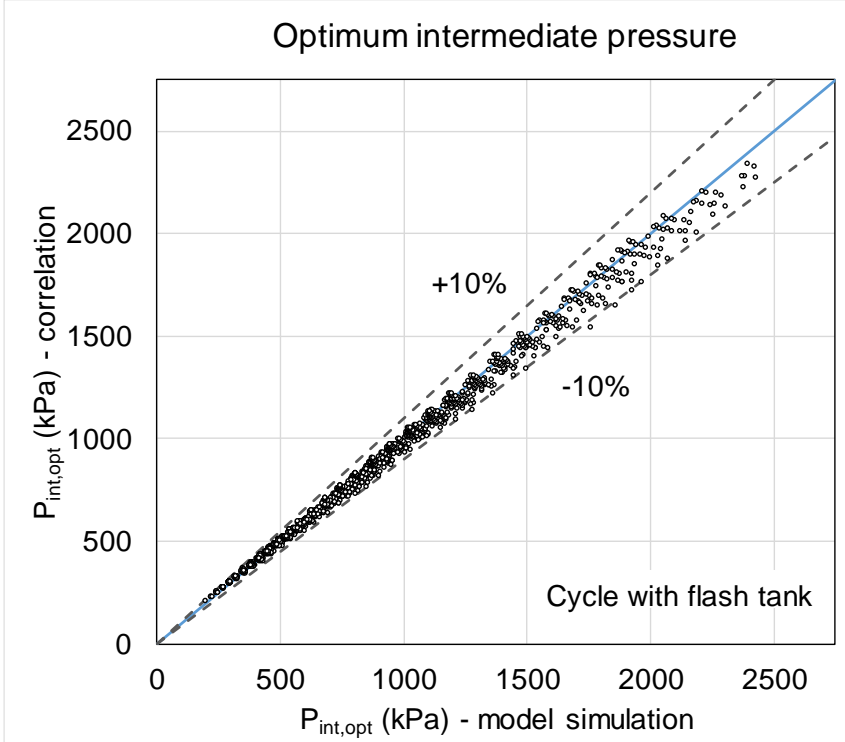

Optimum intermediate dew point temperature
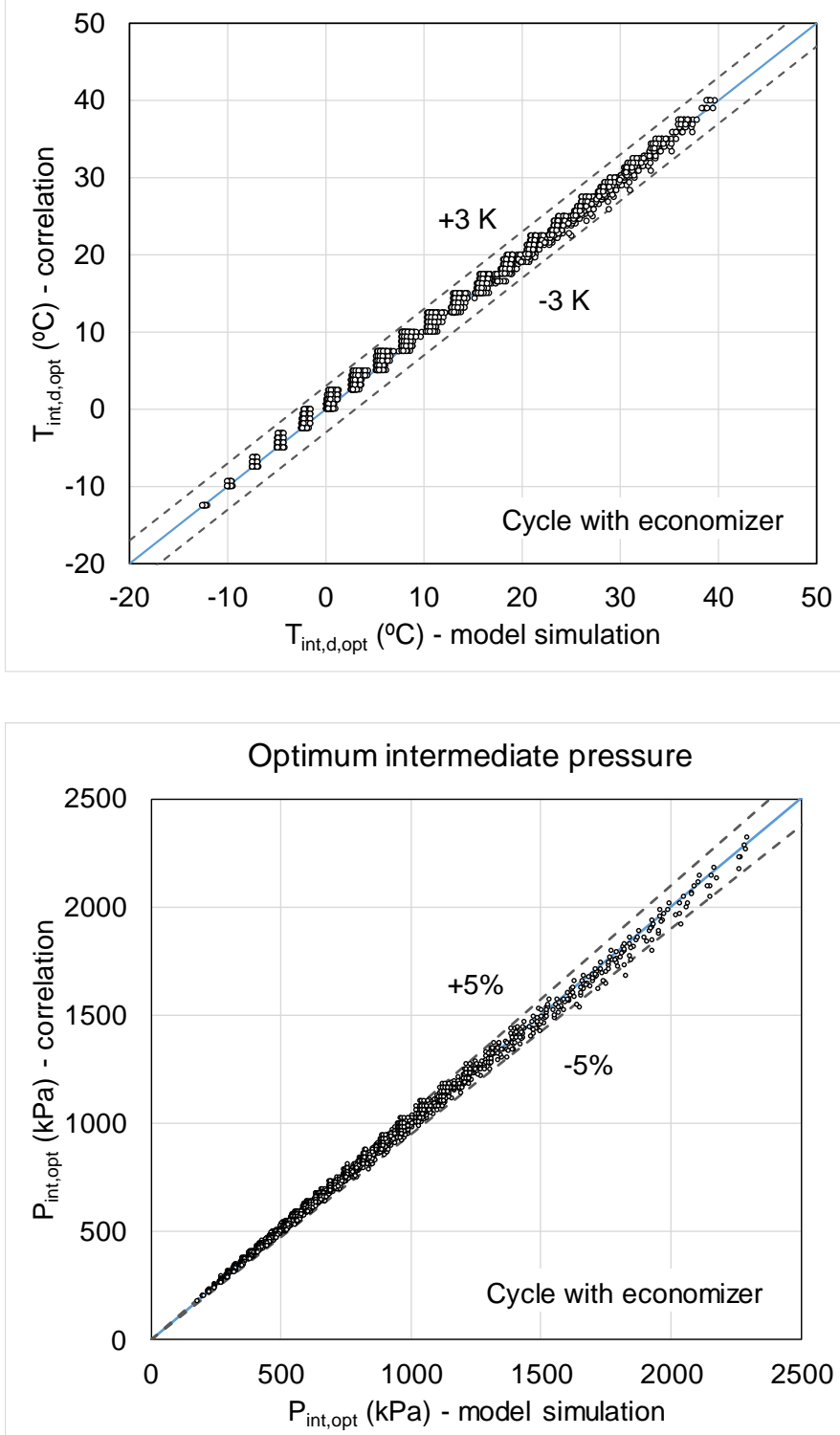

Fig. 6. a) Comparison of the model simulation and correlation results of the $T_{\text {int,d,opt. }}$ b) Comparison of the model simulation and correlation results of the $\mathrm{P}_{\text {int,opt }}$ for cycles with flash tank and economizer.

In order to show the influence of the subcooling on the optimum intermediate pressure and the COP in a heating application, the obtained correlation (21) is used in a model of a two-stage cycle with an economizer. An air to water heat pump for very high-temperature application is simulated, where the conditions of the secondary fluid (water) are an inlet temperature of $45^{\circ} \mathrm{C}$, variable water flow rate and a fixed water temperature lift of $20 \mathrm{~K}$. The heat pump works with R-290 as a refrigerant, the evaporating temperature is assumed constant $\left(-15^{\circ} \mathrm{C}\right)$, and the condensing temperature is fixed by the secondary fluid of the condenser through an energy balance in the condenser. The parameters used in the model are: ideal compressor efficiencies, superheat of $5 \mathrm{~K}$ in the compressor inlet, injection superheat of $5 \mathrm{~K}$, and the economizer has a temperature approach of $5 \mathrm{~K}\left(\mathrm{DT}_{\mathrm{b}}\right)$. 
The model considers a condenser with an infinite heat transfer area. As commented previously, the optimal subcooling for this application is estimated when the condition of having two pinch points of $0 \mathrm{~K}$ between the refrigerant and secondary fluid takes place at the same time in the condenser. This optimal subcooling and the corresponding condensing temperature are used in correlation (21) to calculate the $\mathrm{T}_{\text {int,d.opt }}$ of the cycle for this application.

In addition, the model was simulated with subcooling values between $[0 \mathrm{~K}-28 \mathrm{~K}]$ to show the influence of the subcooling on the optimum intermediate pressure and the $\mathrm{COP}_{\mathrm{h}}$ in the heat pump.

a)

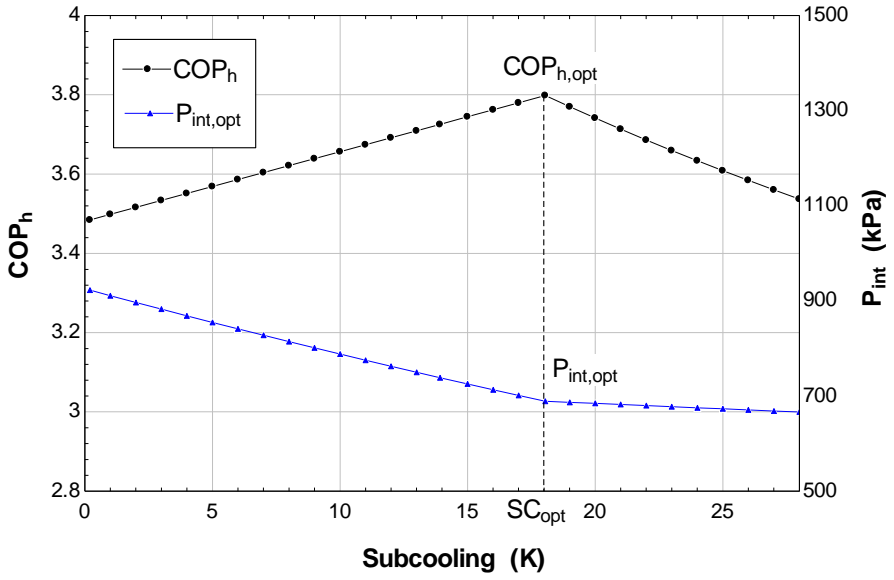

b)

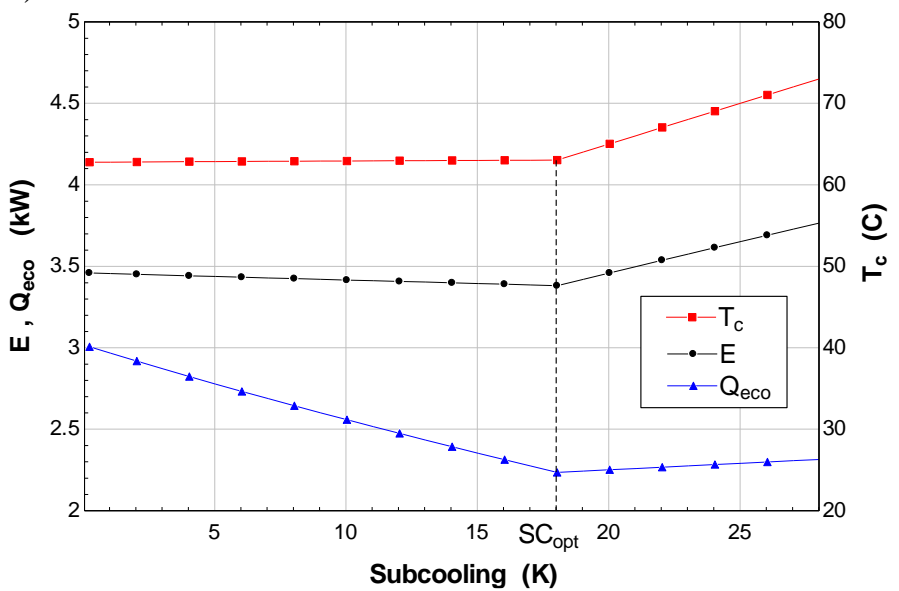

Fig. 7. a) Influence of the subcooling on the $\mathrm{P}_{\text {int,opt }}$ and $\mathrm{COP}_{\mathrm{h}}$. b) Influence of the subcooling on the economizer capacity, compressor power input, and condensing temperature. Ideal heat pump for the heating application $\left(\mathrm{T}_{\mathrm{w}, \mathrm{in}}=45\right.$ $\left.{ }^{\circ} \mathrm{C}, \Delta \mathrm{T}_{\mathrm{w}}=20 \mathrm{~K}\right)$.

Fig. 7(a) depicts an optimum point of the cycle when $\mathrm{SC}=18 \mathrm{~K}$. As subcooling increases, the temperature at the condenser outlet (refrigerant side) decreases and the energy transfer capacity of the economizer is reduced (see Fig. 7(b)). Consequently, in order to maintain the superheat at the economizer outlet, the injection ratio decreases along with the intermediate pressure. Thus, the intermediate pressure decreases as the subcooling increases up to the optimum subcooling. At this point, the temperature at the outlet of the condenser equals the inlet temperature of the secondary fluid, which corresponds to the thermal limit (see pinch point 2 in Fig. 4). For higher values of subcooling, the intermediate pressure is almost constant and the condensing temperature increases as well as the compressor consumption, producing a reduction of the heating COP.

Fig. 7(b) shows the decreasing of the economizer capacity for subcooling values lower than the optimum, and the increasing of condensing temperature and compressor power input for subcooling values higher than the optimum.

For the studied application, the $\mathrm{COP}_{\mathrm{h}}$ improves by $8.5 \%$ when the system works with the optimum subcooling with respect to the system working with $\mathrm{SC}=0$. The optimum intermediate pressure of the cycle is $25 \%$ lower than the intermediate pressure corresponding to the $\mathrm{SC}=0$. These results demonstrate that the optimum point of the cycle cannot be calculated with the 
correlations found in the literature, since they omit the required application conditions. Therefore, the optimum intermediate pressure can be estimated using the proposed correlation (21), where the subcooling and the condensing temperature correspond to the optimal conditions in the condenser, depending on the temperature level and temperature lift of the secondary fluid for a given application. Then the correlation presented in this paper is crucial for determining the real optimum of the system.

One possible way to obtain the optimum subcooling in a two-stage cycle with vapor-injection could be the subcooling control strategy shown in Fig. 8. This strategy is based on a strategy used to optimize the operation of simple refrigeration cycles by changing the refrigerant active charge of the system (Jensen and Skogestad, 2007).

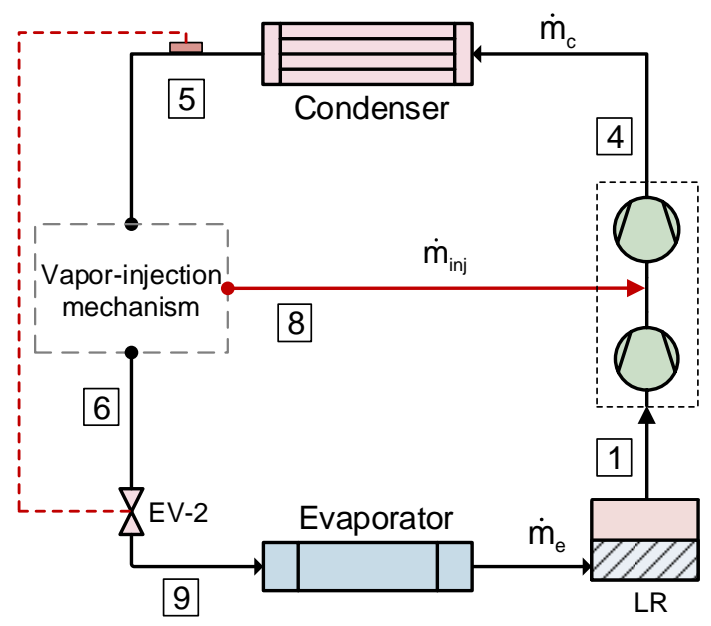

Fig. 8. Control of subcooling for two-stage vapor compression cycle with vapor-injection.

In the case at hand, the system uses a liquid receiver (LR) at the evaporator outlet and the expansion valve (EV-2) does not use the superheat at the compressor inlet as a control variable. Instead, the opening of the expansion valve (EV-2) will determine the subcooling at the condenser outlet, which has an important influence in the optimum COP and its control is crucial in order to obtain a good performance of this type of systems. The subcooling is adjusted by changing the active refrigerant charge of the system (this charge does not include the charge contained in reservoirs like in the liquid receiver). In order to change the active charge of the system, the liquid receiver is used to hold the charge variation under different conditions.

\subsection{Influence of the system components on the COP}

Once the degrees of freedom of the cycle and their respective system variables are known, and focusing on the two-stage cycle with an economizer, the values of these system variables must be set by the components of a real system (compressor, expansion device, economizer, and 
condenser). The following analysis will determine the influence of the selection of each component of the cycle in the operation of the system.

- Second-stage compressor size: the compressor displacements are defined with the displacement ratio $D_{R}$. The influence of the $D_{R}$ on the cycle COP is studied by varying the $\mathrm{D}_{R}$ between $[0.3-1]$, considering typical heating application conditions $\left(\mathrm{T}_{\mathrm{e}}=-15^{\circ} \mathrm{C}\right.$, $\mathrm{T}_{\mathrm{c}}=60{ }^{\circ} \mathrm{C}, \mathrm{SH}=5 \mathrm{~K}$ and $\mathrm{SC}=5 \mathrm{~K}$ ). The effect of the efficiency of the compressors on the $\mathrm{COP}$ can be performed using simple equations that represent the compressors efficiency. However, the present study assumes constant compressor efficiencies.

- Expansion device: the intermediate superheat is generally fixed with a thermostatic expansion valve and the superheat considered for this valve is $5 \mathrm{~K}$.

- Condenser: as commented above, the subcooling at the condenser outlet is an important factor to take into account when finding the optimum intermediate conditions of operation in two-stage cycles with vapor-injection. The influence of the subcooling on the COP and on the optimum intermediate pressure is shown and discussed in the previous section.

- Economizer: when an economizer is included in the two-stage cycle with vapor-injection, which allows a certain injection superheat to be maintained, the degrees of freedom of the cycle are reduced to two, the intermediate pressure and the injection ratio. These two system variables depend on the heat transfer in the economizer, which in turn depends on its size. Consequently, by introducing an economizer in the cycle, a new variable is added to the system, which is the heat exchanger area of the economizer $\left(\mathrm{A}_{\mathrm{eco}}\right)$. Once the system economizer is set, both the intermediate pressure and the injection ratio are defined for a determined injection superheat.

\subsubsection{Displacement ratio of the compressors}

An example of the compressor displacement ratio is presented using refrigerant R-290. According to Table 2, the optimum thermodynamic of the cycle for the R-290 refrigerant is obtained when $\mathrm{D}_{\mathrm{R}}=0.5$ (with $\mathrm{SH}_{\mathrm{int}}=34.46 \mathrm{~K}$ ). Fig. 9 shows the variation of the COP as a function of $\mathrm{D}_{\mathrm{R}}$. The reduction of the COP is more significant if the displacement ratio is lower than the optimum. In this case, if $\mathrm{D}_{\mathrm{R}}=0.2$, the COP decreases by $12 \%$, and if $\mathrm{D}_{\mathrm{R}}=0.8$ the COP decreases by $2 \%$. 


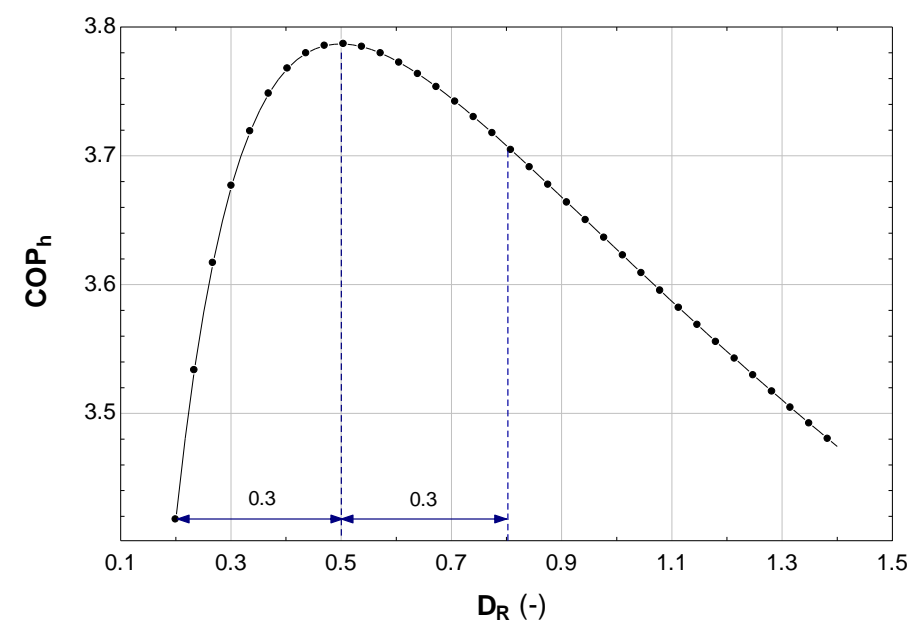

Fig. 9. Variation of the $\mathrm{COP}$ as a function of the displacement ratio. Ideal system with $\mathrm{DT}_{\mathrm{b}}=0 \mathrm{~K}, \mathrm{DT}_{\mathrm{d}}=0 \mathrm{~K}$. Working condition $\left(\mathrm{T}_{\mathrm{e}}=-15^{\circ} \mathrm{C}, \mathrm{T}_{\mathrm{c}}=60^{\circ} \mathrm{C}, \mathrm{SH}=5 \mathrm{~K}, \mathrm{SC}=5 \mathrm{~K}\right.$ and $\left.\mathrm{SH}_{\mathrm{int}}=34.46 \mathrm{~K}\right)$. Refrigerant R-290.

In the case of the system with $\mathrm{SH}_{\mathrm{in}}=5 \mathrm{~K}$, the optimum COP is obtained with $\mathrm{D}_{\mathrm{R}}=0.48$ and $X_{\mathrm{inj}}=0.27$. Fig. 10 shows the variation of the $\mathrm{COP}$ as a function of the injection ratio for several $D_{R}$. The working map is limited by the line corresponding to $D_{b}=0 \mathrm{~K}$ (see dashed line in Fig. 10). Once $D_{R}$ is set, the system can only work on the line corresponding to that $D_{R}$. Therefore, when the system works with a different $\mathrm{X}_{\mathrm{inj}}$, the COP decreases (see line corresponding to $D_{R}=0.48$ in Fig. 10). In this case, for $X_{i n j}=0.2$, the COP reduces by $5.3 \%$.

In the case of a cycle with an economizer, whose temperature approach is $5 \mathrm{~K}\left(\mathrm{DT}_{\mathrm{b}}\right)$, the optimum COP decreases by $1.6 \%$, and it is obtained when $D_{R}=0.51$ and $X_{\text {inj }}=0.26$ (see line corresponding to $\mathrm{DT}_{b}=5 \mathrm{~K}$ in Fig. 10). In this case also, for lower values of $\mathrm{X}_{\mathrm{inj}}$, the COP will decrease.

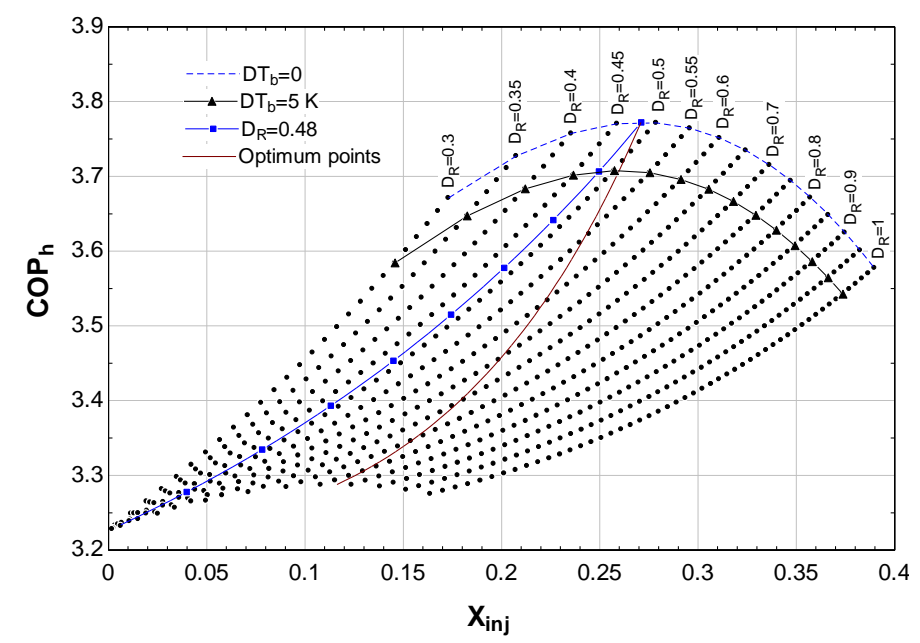

Fig. 10. Variation of the $\mathrm{COP}$ as a function of the injection ratio for several displacement ratios. Working condition $\left(\mathrm{T}_{\mathrm{e}}=-15^{\circ} \mathrm{C}, \mathrm{T}_{\mathrm{c}}=60^{\circ} \mathrm{C}, \mathrm{SH}=5 \mathrm{~K}, \mathrm{SC}=5 \mathrm{~K}\right.$ and $\left.\mathrm{SH}_{\mathrm{int}}=5 \mathrm{~K}\right)$.

Refrigerant R-290. 


\subsubsection{Economizer size}

As can be seen in Table 2, for most of the studied refrigerants except for R-32 and R-22, the optimum thermodynamic of a two-stage cycle is obtained when $\mathrm{DT}_{\mathrm{b}}$ and $\mathrm{DT}_{\mathrm{d}}$ are equal to zero. This condition would be fulfilled in a cycle with an economizer with an infinite heat exchanger area. However, in real systems, the economizer of two-stage cycles with vapor-injection has a certain size and therefore the performance of the system depends on the heat transfer area of the economizer.

In this analysis, the heat exchanger model described in section 2 is used to simulate the economizer in a two-stage cycle with vapor-injection. In this cycle configuration, the intermediate pressure is controlled in order to maintain a certain injection superheat at the economizer outlet. Therefore, the $\mathrm{SH}_{\text {int }}$ is defined as an additional parameter, which is fixed to $5 \mathrm{~K}$. The other parameters considered are the superheat at the evaporator outlet of $5 \mathrm{~K}$, the subcooling at the condenser outlet of $5 \mathrm{~K}$, and the working point considered is $\left(\mathrm{T}_{\mathrm{e}}=-15^{\circ} \mathrm{C}, \mathrm{T}_{\mathrm{c}}=60^{\circ} \mathrm{C}\right)$.

The plate geometry introduced in the heat exchanger model of the economizer is obtained from catalog data of a brazed plate heat exchanger model B8T from SWEP manufacturer (SWEP, 2017).

Generally, the two-stage cycles with economizer are designed in order to have a temperature approach in the economizer of $5 \mathrm{~K}\left(\mathrm{DT}_{\mathrm{b}}\right)$. Therefore, in this analysis, the intermediate pressure has been optimized and the heat exchange area $\left(\mathrm{A}_{\text {eco }}\right)$ of the economizer has been found in order to achieve this temperature approach in the economizer for the given working conditions. The heat transfer area can be modified in the model by varying the number of plates of the heat exchanger $(\mathrm{Np})$.

Table 4 shows the optimization results of the ideal cycle with an economizer. For all refrigerants, the optimal intermediate pressure is higher than the geometric mean of the condensing and evaporating pressure $\left(C_{0}>1\right)$. Nevertheless, the optimum intermediate pressure is lower than the intermediate pressure corresponding to the optimum thermodynamic of the two-stage cycle of Table 2, except the refrigerant R-1234yf.

The displacement ratio in the optimum conditions depends on the refrigerant. For all the studied refrigerants (except for R-1234yf), the displacement ratio in the economizer cycle is higher than the optimum thermodynamic of the two-stage cycle of Table 2. The compressor size is greater when it works in an economizer cycle with respect to the optimum of the two-stage cycle.

The system with R-32 requires a smaller heat exchanger area, followed by the system with refrigerants R-290, R-22 and R-134a. The system working with R-407C needs a greater heat exchanger area in the economizer, followed by the systems working with R-1234yf and R-410A. The system working with R-410A and R-32 present higher economizer capacity than the rest of the refrigerants. The cycle with R-1234yf reaches the highest improvement in capacity and COP 
(42\% and $18 \%$ respectively) with respect to the single-stage cycle. However, for all the studied refrigerants, the improvement in heating capacity and COP is lower than the improvement of the optimum thermodynamic results, as expected (see Table 2). The system with R-32 presents the highest discharge temperature $\left(>115{ }^{\circ} \mathrm{C}\right)$ and the system with R-1234yf presents the lowest discharge temperature $\left(<65^{\circ} \mathrm{C}\right)$.

Table 4 Two-stage cycle with economizer working in optimum intermediate conditions for the working point $\left(\mathrm{T}_{\mathrm{e}}=-15^{\circ} \mathrm{C}, \mathrm{T}_{\mathrm{c}}=60^{\circ} \mathrm{C}, \mathrm{SH}=5 \mathrm{~K}, \mathrm{SC}=5 \mathrm{~K}\right.$ and $\left.\mathrm{SH}_{\text {int }}=5 \mathrm{~K}\right)$.

\begin{tabular}{|l|c|c|c|c|c|c|c|c|c|c|c|c|c|c|c|c|c|}
\hline \multicolumn{1}{|c|}{$\mathrm{REF}$} & $\begin{array}{c}\mathrm{X}_{\text {inj }} \\
(-)\end{array}$ & $\begin{array}{c}\mathrm{SH}_{\mathrm{inj}} \\
(\mathrm{K})\end{array}$ & $\begin{array}{c}\mathrm{P}_{\text {int }} \\
(\mathrm{kPa})\end{array}$ & $\begin{array}{c}\mathrm{DT}_{\mathrm{b}} \\
(\mathrm{K})\end{array}$ & $\begin{array}{c}\mathrm{DT}_{\mathrm{d}} \\
(\mathrm{K})\end{array}$ & $\begin{array}{c}\mathrm{C}_{\mathrm{o}} \\
(-)\end{array}$ & $\begin{array}{c}\mathrm{Np} \\
(-)\end{array}$ & $\begin{array}{c}\mathrm{A}_{\text {eco }} \\
\left(\mathrm{m}^{2}\right)\end{array}$ & $\begin{array}{c}\mathrm{Q}_{\mathrm{eco}} \\
(\mathrm{kW})\end{array}$ & $\begin{array}{c}\mathrm{T}_{\text {int,d }} \\
\left({ }^{\circ} \mathrm{C}\right)\end{array}$ & $\begin{array}{c}\mathrm{D}_{\mathrm{R}} \\
(-)\end{array}$ & $\begin{array}{c}\mathrm{T}_{\mathrm{dis}} \\
\left({ }^{\circ} \mathrm{C}\right)\end{array}$ & $\begin{array}{c}\dot{\mathrm{Q}}_{\mathrm{h}} \\
(\mathrm{kW})\end{array}$ & $\begin{array}{c}\mathrm{COP}_{\mathrm{h}} \\
(-)\end{array}$ & $\begin{array}{c}\theta \\
(-)\end{array}$ & $\begin{array}{c}\mathrm{DQ}_{\mathrm{h}} \\
(\%)\end{array}$ & $\begin{array}{c}\mathrm{DCOP}_{\mathrm{h}} \\
(\%)\end{array}$ \\
\hline $\mathrm{R}-407 \mathrm{C}$ & 0.26 & 5.00 & 874.61 & 5.00 & 26.03 & 1.07 & 56 & 1.24 & 2.63 & 19.81 & 0.44 & 83.84 & 12.77 & 3.66 & 0.46 & 32.10 & 14.20 \\
\hline $\mathrm{R}-22$ & 0.22 & 5.00 & 881.07 & 5.00 & 31.16 & 1.04 & 34 & 0.74 & 2.42 & 18.84 & 0.48 & 95.03 & 13.89 & 3.74 & 0.45 & 25.70 & 11.20 \\
\hline $\mathrm{R}-290$ & 0.26 & 5.00 & 824.33 & 5.00 & 30.56 & 1.05 & 32 & 0.69 & 2.62 & 19.44 & 0.51 & 71.56 & 12.23 & 3.71 & 0.46 & 33.60 & 14.90 \\
\hline R-410A & 0.28 & 5.00 & 1474.41 & 5.00 & 29.12 & 1.09 & 50 & 1.10 & 4.57 & 20.79 & 0.49 & 92.69 & 21.10 & 3.52 & 0.48 & 34.70 & 15.30 \\
\hline R-134a & 0.25 & 5.00 & 555.04 & 5.00 & 30.97 & 1.06 & 34 & 0.74 & 1.74 & 19.03 & 0.42 & 72.09 & 8.26 & 3.76 & 0.45 & 32.90 & 14.50 \\
\hline R-32 & 0.23 & 5.00 & 1459.09 & 5.00 & 30.38 & 1.05 & 26 & 0.55 & 3.85 & 19.62 & 0.50 & 118.40 & 22.89 & 3.57 & 0.46 & 25.00 & 10.90 \\
\hline
\end{tabular}

In order to analyze how the COP changes when the system works with intermediate conditions different from the optimal intermediate conditions, the cycle was simulated for several values of $T_{\text {int,d }}$ and $X_{\text {inj }}$ for a given heat transfer area of the economizer. The $X_{\text {inj }}$ varies between $[0.1-0.3]$ and the $\mathrm{T}_{\text {int, }}$ between $\left[10^{\circ} \mathrm{C}-34^{\circ} \mathrm{C}\right]$. Fig. 11 illustrates the contour map of the COP as a function of the normalized parameters ( $\mathrm{X}^{\prime}{ }_{\text {inj }}$ and $\mathrm{T}^{\prime}{ }_{\text {int,d }}$ ) for refrigerants $\mathrm{R}-290$ and $\mathrm{R}-32$, refrigerants considered representative of their corresponding groups.

In the case of the R-290 refrigerant (Fig. 11a), the continuous line shows the working points of the system when a constant value of $\mathrm{DT}_{b}=5 \mathrm{~K}$ is assumed as a temperature approach of the economizer. This assumption is generally adopted in order to simplify the heat transfer in the economizer. However, this line does not exactly represent the behavior of the system when working with different intermediate pressures.

The dashed line shows the working points of the system for several intermediate conditions when the heat transfer area of the economizer is defined $\left(0.69 \mathrm{~m}^{2}\right)$. In this case, the dashed line has a different slope from the continuous line $\left(\mathrm{DT}_{b}=5 \mathrm{~K}\right)$, since the temperature approach of the economizer $\left(\mathrm{DT}_{\mathrm{b}}\right)$ and the overall heat transfer coefficient $(\mathrm{U})$ change as a function of the intermediate conditions. The same behavior is observed for the refrigerant R-32 of Fig. 11b. Consequently, the assumption of having a temperature approach of $5 \mathrm{~K}$ in the economizer is valid only for a single point (design point), and it does not take into account the influence of the heat transfer area of the economizer. 
Fig. 11 also shows the operating lines of the system when working with different heat transfer areas of the economizer. The optimal point of the cycle with the economizer is reached in the line of $\mathrm{DT}_{b}=0 \mathrm{~K}$, which means an infinite heat transfer area. However, in a real system, the heat transfer area of the economizer is fixed. The results show that the maximum $\mathrm{COP}_{\mathrm{h}}$ increases as the economizer area increases. For R-290 refrigerant, the $\mathrm{COP}_{\mathrm{h}, \max }$ increases from 3.66 to 3.74 for economizer areas from $0.32 \mathrm{~m}^{2}$ to $1.38 \mathrm{~m}^{2}$ respectively, that is, $2 \%$ of $\mathrm{COP}_{\mathrm{h}}$ improvement by more than four times the initial heat transfer area of the economizer.

a)

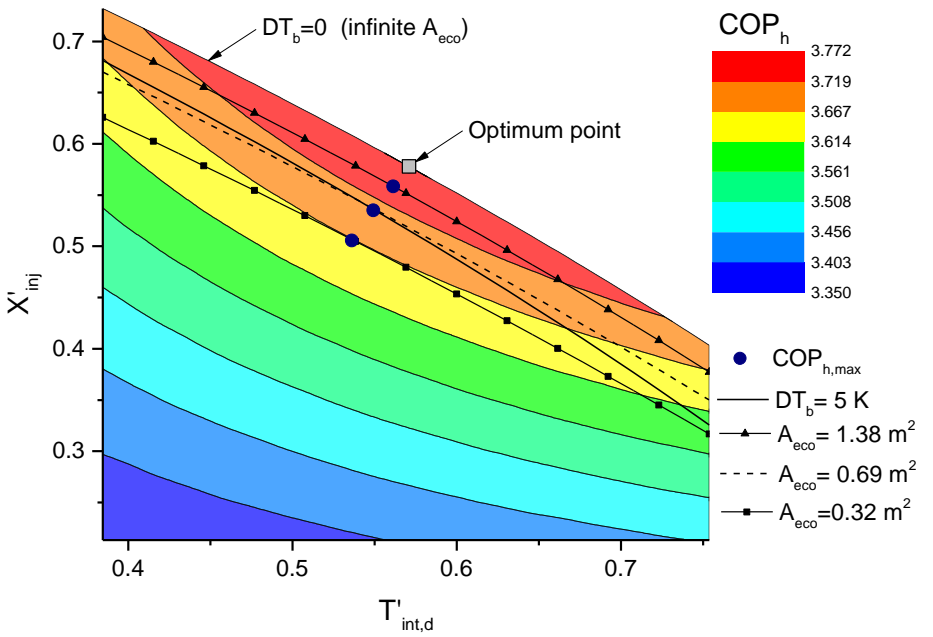

b)

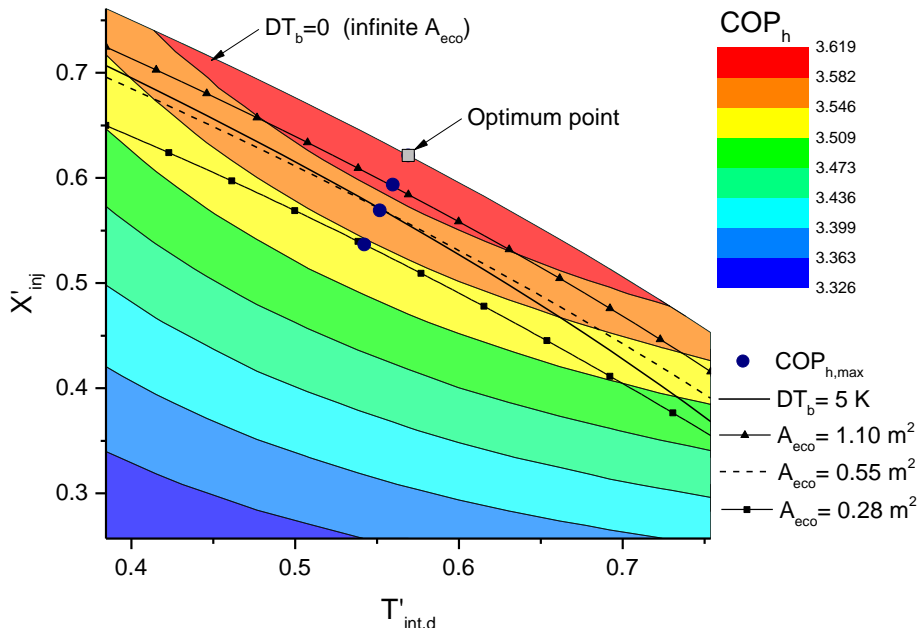

Fig. 11. Contour maps of $\mathrm{COP}$ as a function of normalized injection ratio and normalized intermediate saturation temperature at the working condition $\left(\mathrm{T}_{\mathrm{e}}=-15^{\circ} \mathrm{C}, \mathrm{T}_{\mathrm{c}}=60{ }^{\circ} \mathrm{C}, \mathrm{SH}=5 \mathrm{~K}, \mathrm{SC}=5 \mathrm{~K}\right.$ and $\left.\mathrm{SH}_{\mathrm{int}}=5 \mathrm{~K}\right)$. a) Refrigerant R-290. b) Refrigerant R-32.

In order to show the influence of the heat transfer area of the economizer on the maximum $\mathrm{COP}_{\mathrm{h}}$, the system was simulated with various numbers of plates of the economizer. Table 5 shows the simulation results for the working point $\left(\mathrm{T}_{\mathrm{e}}=-15{ }^{\circ} \mathrm{C}, \mathrm{T}_{\mathrm{c}}=60{ }^{\circ} \mathrm{C}, \mathrm{SH}_{\mathrm{int}}=5 \mathrm{~K}, \mathrm{SC}=5 \mathrm{~K}\right)$ with $\mathrm{R}-290$ as a refrigerant. For this parametric study, the number of plates of the heat exchanger (economizer) was varied from 12 to 84 using the economizer model described in section 2 . The results indicate that the intermediate pressure and the injection ratio increase as the economizer size increases. 
Table 5 Optimum intermediate conditions of a two-stage cycle with an economizer for various numbers of plates of the economizer. Working point $\left(\mathrm{T}_{\mathrm{e}}=-15^{\circ} \mathrm{C}, \mathrm{T}_{\mathrm{c}}=60^{\circ} \mathrm{C}, \mathrm{SH}=5 \mathrm{~K}, \mathrm{SC}=5 \mathrm{~K}\right.$ and $\mathrm{SH}_{\text {int }}=5 \mathrm{~K}$ ) with $\mathrm{R}-290$.

\begin{tabular}{|c|c|c|c|c|c|c|c|c|c|c|c|}
\hline $\begin{array}{l}N_{p} \\
(-)\end{array}$ & $\begin{array}{l}\mathrm{A}_{\text {eco }} \\
\left(\mathrm{m}^{2}\right)\end{array}$ & $\begin{array}{l}\mathrm{DT}_{\mathrm{b}} \\
(\mathrm{K})\end{array}$ & $\begin{array}{l}\mathrm{DT}_{\mathrm{d}} \\
(\mathrm{K})\end{array}$ & $\begin{array}{l}\mathrm{C}_{0} \\
(-)\end{array}$ & $\begin{array}{c}X_{\text {inj }} \\
(-)\end{array}$ & & $\begin{array}{c}\mathrm{P}_{\text {int }} \\
(\mathrm{kPa})\end{array}$ & $\begin{array}{l}\mathrm{T}_{\text {int,d }} \\
\left({ }^{\circ} \mathrm{C}\right)\end{array}$ & $\begin{array}{c}\dot{\mathrm{Q}}_{\mathrm{h}} \\
(\mathrm{kW})\end{array}$ & $\begin{array}{c}\mathrm{COP}_{\mathrm{h}, \mathrm{opt}} \\
(-)\end{array}$ & $\begin{array}{c}\dot{\mathrm{Q}}_{\mathrm{eco}} \\
(\mathrm{kW})\end{array}$ \\
\hline 12 & 23 & 98 & 0.25 & 1.06 & 0.23 & 5.00 & 831.11 & \begin{tabular}{|l|l|}
19.75 \\
\end{tabular} & 11.74 & 3.642 & 2.20 \\
\hline 16 & 3 & 14 & & 07 & 24 & & & & & & 13 \\
\hline 20 & & & & 07 & & & & & 1. & & .40 \\
\hline 24 & & & & & & & & & L. & & .4. \\
\hline 28 & & & & 1.09 & & 0 & & & 2.06 & & .48 \\
\hline 32 & & & 29.00 & 1.09 & & 500 & & .00 & 12.08 & & 2.51 \\
\hline 36 & & 51 & 900 & 1.09 & 25 & 5.00 & & 1.00 & 12.12 & & 54 \\
\hline 40 & & 14 & 29.00 & 1.09 & 26 & 5.00 & 85 & 21.00 & 12.15 & & 2.57 \\
\hline 44 & & 5 & 29. & 1.09 & 0.26 & 5.00 & & 21.00 & 12.2 & & 2.61 \\
\hline 48 & & & & 1. & .26 & 5.00 & 864 & 21.25 & 12 . & .729 & 2.62 \\
\hline 52 & & & & 1. & 2 & 5.0 & 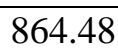 & 21.25 & 12.2 & 7 & 2.6 \\
\hline 56 & & 6 & 28.75 & 1 & 2 & $5 .($ & 8 & 21.25 & 12. & & 2.60 \\
\hline 60 & & & & & & 0 & & 50 & 12.26 & & 2.67 \\
\hline 64 & & 22 & 28.50 & 11 & 6 & 5.00 & & 21.50 & 12.28 & 43 & 2.68 \\
\hline 68 & 1 & 2.03 & 28.50 & 1.11 & & 5.00 & & 21.50 & 12.3 & 746 & 2.69 \\
\hline 72 & & 1.86 & 28.50 & 1.1 & & 5.00 & 870 & 21.50 & 12.31 & .748 & 2.71 \\
\hline 76 & 1.7 & 71 & 28.50 & 1.11 & 26 & 5.00 & 870.14 & 21.50 & 12.32 & 3.750 & 2.72 \\
\hline 80 & & 57 & 28.25 & 1.1 & 0.2 & 5.00 & & 21.75 & 12.31 & 3.751 & 2.72 \\
\hline 84 & 1.89 & 1.45 & 28.25 & 1.12 & 0.27 & 5.00 & 875.82 & 21.75 & 12.32 & 3.753 & 2.72 \\
\hline
\end{tabular}

Fig. 12 illustrates the variation of the $\mathrm{COP}_{\mathrm{h}, \mathrm{opt}}$ as a function of the number of plates of the economizer. Fig. 12(a) shows that the $\mathrm{COP}_{\mathrm{h}, \mathrm{opt}}$ increases as the number of plates of the economizer increases. However, from a certain point (around $\mathrm{N}_{\mathrm{p}}=32$ ), the increase rate of $\mathrm{COP}_{\mathrm{h}, \mathrm{opt}}$ declines while the area of the economizer grows with a constant slope. Fig. 12(b) shows the variation of $\mathrm{DT}_{\mathrm{b}}$ as a function of the number of plates of the economizer. As the number of plates increases, $\mathrm{DT}_{\mathrm{b}}$ decreases asymptotically. Nevertheless, the selection of economizer size is limited by technical and economic reasons.

a)

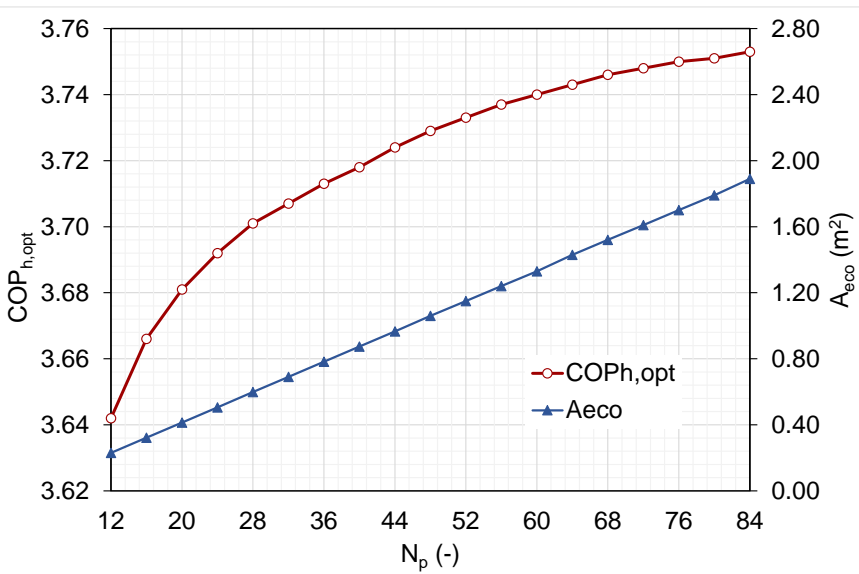

b)

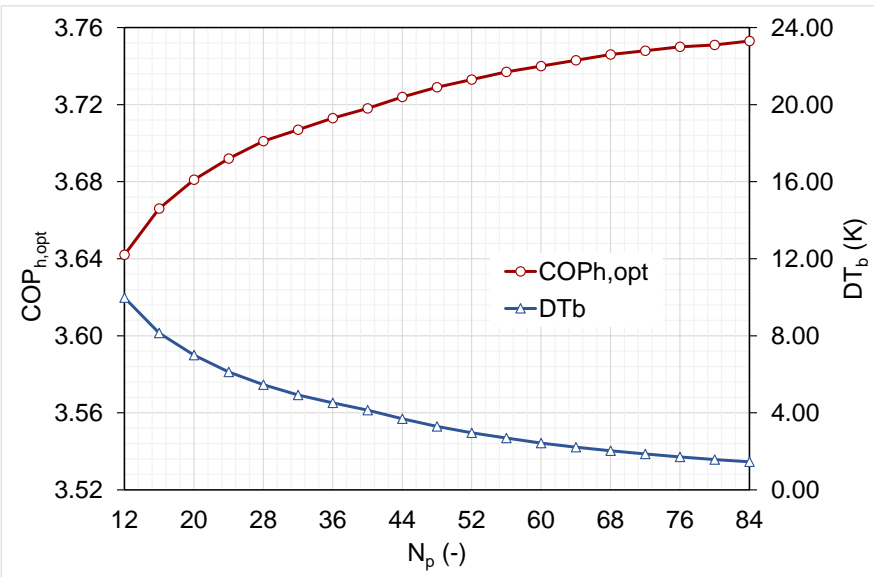

Fig. 12. a) Variation of the $\mathrm{COP}_{\mathrm{h}, \mathrm{opt}}$ and the economizer area as a function of $\mathrm{N}_{\mathrm{p}}$. b) Variation of the $\mathrm{DT}_{\mathrm{b}}$ as a function of $\mathrm{N}_{\mathrm{p}}$. Working point $\left(\mathrm{T}_{\mathrm{e}}=-15^{\circ} \mathrm{C}, \mathrm{T}_{\mathrm{c}}=60^{\circ} \mathrm{C}, \mathrm{SH}=5 \mathrm{~K}, \mathrm{SC}=5 \mathrm{~K}\right.$ and $\left.\mathrm{SH}_{\text {int }}=5 \mathrm{~K}\right)$ with $\mathrm{R}-290$. 


\section{CONCLUSIONS}

In this paper, a study of two-stage cycles with vapor-injection is presented. The study gives answers to different questions proposed in the introduction. The influential parameters on the system design and performance were identified. In addition, the influence of these parameters on the heating COP was determined, and the optimum intermediate pressure of the two-stage cycle with vapor-injection was analyzed, taking into account the influence of the subcooling, and finally, the influence of the components design on the cycle efficiency is established.

The following conclusions can be drawn from this study:

- Two-stage cycles with vapor-injection present three degrees of freedom. The intermediate pressure, the injection mass flow rate and the injection temperature were chosen as variables of study because it is feasible to control these physical or engineering parameters in a conventional installation. Cycle performance variables can be expressed as a function of $\mathrm{T}_{\mathrm{int,d}}, \mathrm{X}_{\mathrm{inj}}$, and $\mathrm{SH}_{\mathrm{inj}}$ respectively.

- The more influential variables on the optimum COP of two-stage cycles with vaporinjection are the injection ratio and the intermediate pressure. The injection superheat has little influence on the COP variation. For all the studied refrigerants, the optimal intermediate pressure is higher than the geometric mean of the condensing and evaporating pressure $\left(\mathrm{C}_{\mathrm{o}}>1\right)$.

- An optimal subcooling was identified in the condenser considering the temperature lift of the secondary fluid. The optimal subcooling must be considered in the estimation of the optimum intermediate pressure in two-stage cycles with vapor-injection.

- A simple correlation was found in order to estimate the optimum intermediate pressure in two-stage cycles with vapor-injection for all the studied refrigerants. The correlation depends on the condensing and evaporating temperatures and, for the first time, the subcooling was included in the correlation. The proposed correlation can be used for both flash tank and economizer cycles.

- An optimum subcooling control strategy is proposed. The subcooling is adjusted by changing the refrigerant charge in the system. To achieve that, a liquid receiver is used at the evaporator outlet and the subcooling is used as a control variable of the expansion valve (evaporator line).

- The two-stage cycle with vapor-injection presents an optimum $\mathrm{COP}_{\mathrm{h}}$ for a specific $\mathrm{D}_{\mathrm{R}}$. When the system works with a different $\mathrm{D}_{\mathrm{R}}$, the reduction of the $\mathrm{COP}_{\mathrm{h}}$ is more significant if the displacement ratio is lower than the optimum one.

- The optimum $\mathrm{COP}_{\mathrm{h}}$ increases as the number of plates of the economizer increases. However, the selection of the economizer size is limited by technical and economic 
reasons. For the heating application conditions $\left(\mathrm{T}_{\mathrm{e}}=-15{ }^{\circ} \mathrm{C}, \mathrm{T}_{\mathrm{c}}=60{ }^{\circ} \mathrm{C}\right)$, the system with R-32 requires a smaller heat exchanger area of the economizer, followed by the system with refrigerants R-290, R-22, and R-134a. The system working with R-407C needs a greater heat exchanger area in the economizer, followed by the systems working with R$1234 \mathrm{yf}$ and R-410A.

\section{Acknowledgments}

Fernando M. Tello-Oquendo acknowledges the financial support provided by the CONVOCATORIA ABIERTA 2013-SEGUNDA FASE program, which was funded by the SENESCYT (Secretaría de Educación Superior, Ciencia, Tecnología e Innovación) (Grant No 2015-AR37665) of Ecuador.

\section{REFERENCES}

Arora, A., Kaushik, S. C., 2010. Energy and exergy analyses of a two-stage vapour compression refrigeration system. Int. J. Energy Res. 34, 907-923.

Ayub, Z. H., 2003. Plate Heat Exchanger Literature Survey and New Heat Transfer and Pressure Drop Correlations for Refrigerant Evaporators. Heat Transfer Eng. 24, 3-16.

Baumann, K., Blass, E., 1961. Beitrag zur Ermittlung des Optimalen Mitteldruckes bei zweistufigen Kaltdampf Verdichter-Kältemaschinen. Kältetechnik 13, 210-216.

Behringer, H., 1928. Berechnung des günstigsten zwischendruckes bei verbundkompresion für NH3-kältemaschinen. Zeitschrift fur die Gesamte Kalte-Industrie 35, 111-113.

Bertsch, S., Groll, E., 2008. Two-stage air-source heat pump for residential heating and cooling applications in northern U.S. climates. Int. J. Refrigeration 31, 1282-1292.

Czaplinski, S., 1959. Uber den optimalen Zwischendruck bei. Allgemeine Wärmetechnik 91, 36.

De Lepeleire, G., 1973. Une nouvelle façon d'appréciation et de sélection des compresseurs frigorifiques biétagés. In: XIII International Congress of Refrigeration. Washington, pp. 3948.

Domanski, P., 1995. Theoretical evaluation of the vapor compression cycle with liquidline/suction-line heat exchanger, economizer, and ejector. NIST Interagency Report 5606. National Institute of Standards and Technology.

EN 12900, 2014. Refrigerant compressors-rating conditions, tolerances and presentation of manufacturer's performance data.

European Commission. Heating and cooling. https://ec.europa.eu/energy/en/topics/energyefficiency/heating-and-cooling [accessed 1503 2017].

European Directive 2009/28/EC of The European Parliament and of The Council. eurlex.europa.eu. 
F-Chart Software. Engineering Equation Solver (EES), Academic Professional V10.091.

Heo, J., Kang, H., Kim, Y., 2012. Optimum cycle control of a two-stage injection heat pump with a double expansion sub-cooler. Int. J. Refrigeration 35, 58-67.

Jensen, J. B., Skogestad, S., 2007. Optimal operation of simple rerigeration cycles Part II: Selection of controlled variables. Comput. Chem. Eng. 31, 1590-1601.

Jiang, S., Wang, S., Jin, X., Yu, Y., 2016. The role of the optimum intermediate pressure in the design of two-stage vapor compression systems: A further investigation. Int. J. Refrigeration 70, 57-70.

Jiang, S., Wang, S., Jin, X., Zhang, T., 2015. A general model for two-stage vapor compression heat pump systems. Int. J. Refrigeration 51, 88-102.

Lemmon, E., Huber, M. \& Mc Linden, M., 2010. NIST Standard Reference Database 23: Reference Fluid Thermodynamic and Transport Properties-refprop. Version 9.0. Gaithersburg: National Institute of Standards and Technology, Standard Reference Data Program.

Li, Y., Yu, J., 2016. Theoretical analysis on optimal configurations of heat exchanger and compressor in a two-stage compression air source heat pump system. Appl. Therm. Eng. 96, 682-689.

Ma, G., Chai, Q., Jiang, Y., 2003. Experimental investigation of air-source heat pump for cold regions. Int. J. Refrigeration 26, 12-18.

Ma, G., Zhao, H., 2008. Experimental study of a heat pump system with flash-tank coupled with scroll compressor. Energ. Buildings 40, 697-701.

Nellis, G., Klein, S., 2009. Heat Transfer, first ed. Cambridge University Press, New York.

Ouadha, A., En-Nacer, M., Adjlout, L., Imine, O., 2005. Exergy analysis of a two-stage refrigeration cycle using two natural substitutes of HCFC22. Int. J. Exergy 20(1), 14-30.

Pitarch, M., Hervas, E., Navarro-Peris, E., Gonzálvez-Maciá, J., 2017. Evaluation of optimal subcooling in subcritical heat pump systems. Int. J. Refrigeration 17, 18-31.

Press, W. H., Teukolsky, S. A., Vetterling, W. T., Flannery, B. P., 2007. Numerical Recipes: The Art of Scientific Computing, third ed. Cambridge University Press, New York.

Rasi, A., 1955. La pression intermédiare la plus correcte pour les cycles frigorifiques à deux phases. In: Proceedings of the 9th International Congress of Refrigeration, Paris, pp. 30323039.

Redón, A., Navarro-Peris, E., Pitarch, M., Gonzálvez-Maciá, J., Corberán, J., 2014. Analysis and optimization of subcritical two-stage vapor injection heat pump systems. Appl. Energy 124, 231-240.

SWEP, 2017. Brazed plate heat exchangers SWEP. http://www.swep.net/globalassets/products/b8t/b8t-en.pdf [accesed 2410 2017]. 
Torella, E., Llopis, R., Cabello, R., 2009. Experimental evaluation of the inter-stage conditions of a two-stage refrigeration cycle using a compound compressor. Int. J. Refrigeration 32, 307-315.

Torrella, E., Larumbe, J.A., Cabello, R., Llopis, R., Sanchez, D., 2011. A general methodology for energy comparison of intermediate configurations in two-stage vapour compression refrigeration systems. Energy 36, 4119-4124.

Wang, B., Shi, W., Han, L., Li, X., 2009b. Optimization of refrigeration system with gas-inyected scroll compressor. Int. J. Refrigeration 32, 1544-1554.

Wang, X., Hwuang, Y., Radermacher, R., 2009a. Two-stage heat pump system with vaporinjected scroll compressor using R410A as a refrigerant. Int. J. Refrigeration 32, 1442-1451.

Xu, S., Ma, G., Liu, Q., Liu, Z., 2013. Experiment study of an enhanced vapor injection refrigeration/heat pump system using R32. Int. J. Therm. Sci. 34, 1922-1933.

Xu, X., Hwang, Y., Radermacher, R., 2011. Refrigerant injection for heat pumping/air conditioning systems: literature review and challenges discussions. Int. J. Refrigeration 34, $402-415$.

Zubair, S. M., Yaqub, M., Khan, S. H., 1996. Second-law-based thermodynamic analysis of twostage and mechanical-subcooling refrigeration cycles. Int. J. Refrigeration 19(8), 506-516. 